\title{
A new method for recovering rare earth elements from the hyperaccumulating fern Dicranopteris linearis from China
}

\author{
Bastien JALLY ${ }^{\mathrm{a}, \mathrm{b}}$, Baptiste LAUBIE ${ }^{\mathrm{a}}$, Zeinab CHOUR ${ }^{\mathrm{a}}$, Laurence MUHR ${ }^{\mathrm{a}}$, Rongliang QIU $^{\mathrm{b}}$, \\ Jean Louis MOREL ${ }^{\mathrm{c}}$, Yetao TANG ${ }^{\mathrm{b}}$, Marie-Odile SIMONNOT ${ }^{\mathrm{a} *}$
}

a: Université de Lorraine, CNRS, LRGP, F-54000 Nancy, France

b: School of Environmental Science and Engineering, Sun Yat-Sen University, Guangzhou 510275, China

c: Université de Lorraine, INRAE, LSE, F-54000 Nancy, France

*Corresponding author

Email address: marie-odile.simonnot@univ-lorraine.fr

\begin{abstract}
Hyperaccumulator plants are new alternative sources for elements of interest e.g., nickel, rare-earth elements (REEs), as concentrations in their aerial parts are higher than in common low-grade ores. The fern Dicranopteris linearis naturally grows on former mine tailings in Southern China and is classified as a REE hyperaccumulator. The efficient recovery of REEs is fundamental to ensure economic viability and to limit the environmental impact of the process. This study presents a novel approach for the treatment of the Dicranopteris biomass after incineration to ash to drastically improve the "bio-ore" grade and to generate heat. Ash structure and composition is described, and challenges for efficient recovery of REEs are discussed. A pre-processing step, aiming at rendering the REEs available for extraction, was designed to dissolve aluminum ( $\mathrm{Al}$ ) using concentrated
\end{abstract}


sodium hydroxide $(6 \mathrm{M})$ at an average temperature $\left(80^{\circ} \mathrm{C}\right)$. The operating parameters were investigated through experiment methodology design and parametric studies to build an empirical model. Additional experiments revealed that the formation of insoluble aluminosilicate compounds limited the removal of aluminium. Rinsing the REE-rich residue proved to be effective to increase the REE concentration and was carefully designed. Subsequently, the REEs were extracted under mildly acidic conditions using nitric acid $\left(25^{\circ} \mathrm{C}, \mathrm{pH} 4.8\right)$, producing a valuable solution devoid of aluminium and containing $74 \%$ of the REEs.

Keywords: rare earth elements; Dicranopteris linearis; Recovery; Agromining; Phytomining; hydrometallurgy

\section{Introduction}

The rare earth elements (REEs) are defined by the IUPAC as the 15 lanthanides in addition to scandium (Sc) and yttrium (Y) (Connelly et al., 2005; Gupta and Krishnamurthy, 2005). Their unique properties and their wide range of application in modern technologies have resulted in substantial growth in production over the past two decades (Machacek and Kalvig, 2016).

A significant part of global production (30-40\%) originates from the ion-adsorption deposits in South China (Packey and Kingsnorth, 2016; Yang et al., 2013). These deposits, also called ionadsorption clays (IAC), are the result of intense tropical weathering of granitic rocks and located across seven provinces in southern China. In these deposits, the REEs are present as trivalent cations adsorbed onto clay minerals, and as such readily extracted with electrolytic solutions, typically ammonium sulfate, $\left(\mathrm{NH}_{4}\right)_{2} \mathrm{SO}_{4}$. The main mining techniques employed, mountaintop mining followed by batch and heap leaching, have generated more than $150 \mathrm{~km}^{2}$ of tailings in the 
Guanzhou county alone (Yang et al., 2013). The reclamation and ecological restoration of these areas is an important research topic in China (Chen and Chen, 2020; Huot et al., 2018; Liu et al., 2017). Phytoremediation is contemplated as a modern and environment-friendly approach to the reclamation of damaged ecosystems and is being explored for the IAC tailings (Burges et al., 2018; Cundy et al., 2016; Rodrigues et al., 2019). The cultivation of valuable crops (e.g., fibre or energy crops) ensures economic sustainability of this approach (Vigil et al., 2015). Hyperaccumulator plants, i.e., plants able to concentrate trace metals and metalloids in their aerial parts at extremely high concentrations (Baker et al., 2000), are another type of economic crops that can be used for the recovery of the elements they accumulate.

The fern Dicranopteris linearis (formerly known as Dicranopteris dichotoma) is a known REE hyperaccumulator, with total REEs concentrations in its fronds usually reaching 2 to $3 \mathrm{mg} \mathrm{g}^{-1}$ of which lanthanum (La), neodymium $(\mathrm{Nd})$, cerium $(\mathrm{Ce})$ and praseodymium $(\mathrm{Pr})$ are the most abundant (Liu et al., 2020, 2019; Wang et al., 1997). This fern is a pioneer plant, capable of colonising laterites in the mining areas of Southern China (Li et al., 2013) which makes it a suitable candidate for agriculture on IAC tailings. Extensive research has established data on the uptake, translocation and detoxification mechanisms of REEs by D. linearis (Chen et al., 2019; Guo et al., 1996; Liu et al., 2019; Wang et al., 2005, 1997; Wei et al., 2005, 2001). However, there has been little research about the recovery of REEs from harvested D. linearis biomass, apart from usage of the plant in traditional medicine and handicrafts (Fern, 2019; Ho et al., 2011; Srivastava, 2007), for the production of biochar for agricultural purposes (Mai et al., 2019) or for the synthesis of organic compounds by pyrolysis (Qin et al., 2019). The considerable economic value of REEs may stimulate the development of novel REE recovery processes. To address this challenge, we recently proposed a REE recovery strategy using enhanced ion-exchange extraction from dried $D$. linearis 
biomass (Chour et al., 2018). The process consists of batch leaching of the D. linearis biomass suspended in nitric acid with ion-exchange resin beads. The REEs are adsorbed onto the resin subsequently extracted achieving a $99 \%$ yield. The resin is then eluted using two different acid concentrations to separate aluminum (Al) and other impurities from the REEs in the same manner as described by Ochsenkühn-Petropoulou et al. (2002). In another recent publication, we demonstrated the feasibility of directly leaching $D$. linearis biomass using various extractants (sulfuric acid, citric acid, and EDTA) at various pH levels (Chour et al., 2020). Optimal recovery rates were achieved with sulfuric acid, REE separation was achieved by oxalate precipitation and purification undertaken using calcination ( $98 \%$ REEs) for a total process yield of $75 \%$.

The process pathway presented in the current work uses $D$. linearis ash as the raw starting material. The combustion of hyperaccumulator plants generally has useful improvements: it considerably enriches the bio-ore, it concentrates the target element(s) while providing a heat source, and it avoids interference of organic compounds with purification steps (Barbaroux et al., 2012; Simonnot et al., 2018; Zhang et al., 2016). Therefore, the properties of $D$. linearis ash are described in this work, and strategy for REE recovery was developed. The key challenge for an efficient extraction resides in the fact that $D$. linearis ash is particularly rich in aluminum (Al) and silicon $(\mathrm{Si})$, which together form an amorphous aluminosilicate matrix. This matrix prevents acid leaching in a single step to extract the REEs. Additionally, Al presence is detrimental for downstream purification of REEs because the trivalent form of the $\mathrm{Al}$ cation in acidic solution is similar to the REEs ( $\mathrm{Li}$ et al., 2020; Wang et al., 2018, 2020; Yang and Zhang, 2015). Hence, an efficient and early removal of Al is highly desirable. To address this issue, a hot caustic soda solution is used to dissolve the aluminosilicate matrix akin to the Bayer process (Habashi, 2016). The REEs are expected to remain in the solid phase by forming insoluble hydroxides and/or carbonates at high $\mathrm{pH}$. 
A three-step extraction is proposed as follows: first, a hot caustic soda solution is used to dissolve the aluminosilicate matrix of the ash thereby concentrating the REEs and increasing their availability. Second, the remaining solid is rinsed with water to lower the $\mathrm{pH}$. Third, the rinsed solid is leached using nitric acid $\left(\mathrm{HNO}_{3}\right)$ to extract the REEs. Operating conditions are explored through parametrical studies and design of experiment methodology. Underlying mechanisms for each step are delineated and discussed. Maximization of Al removal is sought in this process to facilitate downstream purification of REEs.

\section{Materials and methods}

\subsection{Plant material}

Wild D. linearis fronds were collected in the mining area of the Dingnan county, Jiangxi Province (China) in October 2018. The fronds were dried at $80{ }^{\circ} \mathrm{C}$ for $72 \mathrm{~h}$ after collection. Several kilograms were ground to approximately $1 \mathrm{~mm}$ with an industrial electric grinder (SECOMI). Aliquots were set aside for elemental analysis. The ground D. linearis material was ashed in multiple batches of approximately $35 \mathrm{~g}$ in a muffle furnace at $550{ }^{\circ} \mathrm{C}$ for $3 \mathrm{~h}$ to ensure complete oxidation. After cooling to room temperature $\left(20^{\circ} \mathrm{C}\right)$ the $D$. linearis ash was collected in a single $2 \mathrm{~L}$ air-tight $\mathrm{PE}$ container. When the quantity of ash was considered sufficient for subsequent experiments $(1 \mathrm{~L})$ the container was manually agitated to ensure homogenization.

\subsection{Chemical and reagents}

Nitric acid was supplied by Fisher Chemicals (67-69\% Optima Grade), while the sodium hydroxide $(\mathrm{NaOH})$ solutions were prepared using $\mathrm{NaOH}$ beads supplied by Sigma Aldrich. Ultrapure water (Elga- Purelab Chorus) was used in all of the experiments. 


\subsection{Analyses}

The elemental composition of the D. linearis dried biomass was determined by inductively coupled plasma optical emission spectrometry (ICP-OES) after $\mathrm{HNO}_{3}$ digestion. Subsamples of approximately $0.1 \mathrm{~g}$ were weighted in borosilicate glass tubes and $5 \mathrm{~mL} \mathrm{HNO}_{3}$ added followed by digestion for $30 \mathrm{~min}$ at $230{ }^{\circ} \mathrm{C}$ and 80 bar pressure in a single chamber microwave (Milestone Ultrawave). After cooling, the solutions were made to volume $(50 \mathrm{~mL})$ in volumetric flasks with deionized water. Filtered solutions (Phenomenex, regenerated cellulose, $0.45 \mu \mathrm{m}$ ) were analyzed with ICP-OES (Thermo iCAP 6000 with Qtegra software). Instrumental calibration was performed in the same manner as described in Chour et al. (2018) using PlasmaCAL ${ }^{\circledR}$ custom standard (SCP Science) in a $5 \mathrm{wt} \%$ of $\mathrm{HNO}_{3}$ matrix. Two solutions were used for all elements (Al, $\mathrm{Co}, \mathrm{Cu}, \mathrm{Fe}$, $\mathrm{Pb}, \mathrm{Mn}, \mathrm{Mg}, \mathrm{Ca}, \mathrm{P}, \mathrm{S}, \mathrm{Ni}, \mathrm{Na}, \mathrm{Zn}$ ) and for the REEs (Y, Sc, and all 14 lanthanides except for Pm), while the calibration for Si was done separately using a Si standard solution (SCP Science). Each measurement was repeated three times and quality-controls checks were performed during the run between every 10 measurements using a known standard solution prepared separately to monitor instrument drift.

Incomplete $\mathrm{HNO}_{3}$ digestion of the ash prior to ICP-OES analysis was noticeable. Thus, preliminary results of the ash analysis were rejected. To overcome this issue, alkaline fluxing, a common technique for dissolving refractory compounds (e.g., silicate matrices), was performed using an automated oven (LeNeo, Claisse). To this end, the ash and the process solids ( $c a 0.1 \mathrm{~g}$ ) were placed into a platinum crucible with $1.97 \mathrm{~g} \mathrm{LiBO}_{2}$ and $0.03 \mathrm{~g} \mathrm{LiBr}$ (Claisse). The crucibles were heat treated at $1050{ }^{\circ} \mathrm{C}$ for $12 \mathrm{~min}$. The melt was poured into an agitated PTFE beaker containing $100 \mathrm{~mL}$ of $10 \% \mathrm{HNO}_{3}$. The solution was transferred into a volumetric flask and made to volume (200 mL). The solution was then analysed by ICP-OES according to the methods described above, 
and by matching the matrices of the standard solutions correctly to account for $\mathrm{LiBO}_{2}$ interferences. Three replicates were used for the determination of biomass and ash composition, and validation was carried out using a certified corn powder standard V463 (USRAVE-INRA).

X-ray diffraction analyses were performed with the Bruker D8-Discover using a Co-anode and linear detection. The PDF-02 database (Powder Diffraction File of International Center for Diffraction Data) was used to identify crystalline phases.

Thermogravimetric analysis (TGA) of the plant biomass was conducted under air, at a constant heating rate of $10^{\circ} \mathrm{C} \mathrm{min}^{-1}$ in a $70 \mu \mathrm{L}$ alumina crucible using a TGA furnace (TGA2 SF, Mettler). Approximately $0.01 \mathrm{~g}$ of the $D$. linearis dried biomass was used for these analyses.

\subsection{Alkaline leaching experiments}

The leaching experiments were performed in a $500 \mathrm{~mL}$ glass vessel equipped with a PTFE magnetic rod. A condenser was installed to avoid evaporation of the liquid and to keep the solid mass fraction constant. The ash aliquots were treated with $\mathrm{NaOH}$ solutions at various temperatures for at least $60 \mathrm{~min}$. A constant solid/liquid ratio of $5 \mathrm{~g} \mathrm{~L}^{-1}$ was used in each experiment. Fresh $\mathrm{NaOH}$ solutions were prepared prior to each experiment to avoid carbonate absorption during storage. After the alkaline treatment, the remaining solid was filtered under vacuum while still hot using cotton filters (Whatman - Grade 40, pore size $8 \mu \mathrm{m}$ ).

The preliminary experiments consisted of parametric studies; under the first set of conditions, $\mathrm{NaOH}$ concentrations of $1,2,3,4$ and $5 \mathrm{M}$ were used at $80^{\circ} \mathrm{C}$ during $3 \mathrm{~h}$. Under the second set of conditions, temperatures of $20,40,60$ and $80^{\circ} \mathrm{C}$ were tested with a $5 \mathrm{M} \mathrm{NaOH}$ solution for a total of $3 \mathrm{~h}$. Small volumes of the suspension were sampled during these experiments to assess the kinetics. 
As the preliminary parametric studies did not result in a satisfactory rate of $\mathrm{Al}$ extraction $(<90 \%)$, in a second phase, the methodological of design of experiment was changed to meet two objectives: (i) to generate an empirical model for Al extraction with respects to operating conditions; and (ii) to continue the extraction rate up to $100 \%$. A composite experimental design was developed taking into account the previously acquired data. Design Expert 11 software (Stat-ease, Inc.) was used to prepare experiments following a centred composite design (three levels and three factors) and to process the data. The three factors were: (i) temperature $\left(75-90^{\circ} \mathrm{C}\right)$; (ii) $\mathrm{NaOH}$ concentration $(4.8-$ $7.2 \mathrm{M}$ ) and (iii) extraction time (13-44 $\mathrm{min}$ ), the alpha value selected was 1.6879 (rotatable design) while the response chosen was the Al extraction rate, based on solution content. During these experiments, the remaining solid was not rinsed, and after each run it was dried for at least $24 \mathrm{~h}$ at $80{ }^{\circ} \mathrm{C}$ in a laboratory oven. The dried solids were crushed using a mortar and pestle and subsequently analysed as described above.

Finally, the impact of carbonation during alkaline leaching was assessed. A low flow of nitrogen gas was bubbled into the reaction medium. The same experiments were conducted with bubbling air as a control. The temperature was maintained at $70{ }^{\circ} \mathrm{C}$ for $1 \mathrm{~h}$ and $6 \mathrm{M} \mathrm{NaOH}$ was used. This part of the experiment was conducted in triplicate.

\subsection{Rinsing}

Screening experiments showed that rinsing the ash after the alkaline leaching step, using deionized water, drastically increased REE concentrations in the solid. Therefore, the previously obtained solids were pooled and analysed for their composition before carefully studying their behaviour during rinsing. A $10 \mathrm{~mm}$-diameter glass column (GE Healthcare Life Science) was filled with $2.79 \mathrm{~g}$ of crushed and dried solids to an initial bed height of $5.4 \mathrm{~cm}$. Deionized water was fed from bottom to top with a volumetric membrane pump at $60 \mathrm{~mL} \mathrm{~h}^{-1}$. The conductivity and $\mathrm{pH}$ of the 
effluent were monitored on-line while the effluent itself was collected with a fraction collector. Fraction volumes were set at $5 \mathrm{~mL}$, but the volumes were corrected after weighting and measuring the density of each of the first 20 fractions. The fractions were analysed by ICP-OES as described earlier.

\subsection{Dissolution}

Dissolution of the REE-rich residue was carried out after the rinsing experiments. Another batch of ash was produced, treated with $6 \mathrm{M} \mathrm{NaOH}$ for 60 min at $70{ }^{\circ} \mathrm{C}$. The collected solid was rinsed on the filter using hot deionized water. After drying and crushing, a suspension of the solid was prepared $\left(\mathrm{S} / \mathrm{L}=2.5 \mathrm{~g} \mathrm{~L}^{-1}\right)$ and the $\mathrm{pH}$ titration was conducted with an automatic titrator (METTLER-Toledo T5) with 0.1 $\mathrm{N} \mathrm{HNO}_{3}$. Due to the slow and uneven kinetics, large, fixed time increments $(\Delta t=300 \mathrm{~s})$ while small acid volume increments $(\Delta \mathrm{V}=0.05 \mathrm{~mL})$ were used to ensure that equilibrium was reached at each step. Acid was added until $\mathrm{pH} 2$ was reached. Small volume aliquots $(0.5 \mathrm{~mL})$ were syringe-filtered (Phenomenex, regenerated cellulose, $0.45 \mu \mathrm{m})$, properly diluted, and analysed with ICP-OES throughout the experiment.

\subsection{Thermodynamic calculations}

All thermodynamic calculations were conducted using the JCHESS software (van der Lee and De Windt, 2002) and the default database adapted from the EQ3/6 version 8 (Wolery and Jarek, 2003). 


\section{Results and discussion}

\subsection{Plant and ash characterization}

The biomass composition of $D$. linearis was similar to previously published data (Table 1) and the sum of the concentration of the 17 REEs was $2.7 \mathrm{mg} \mathrm{g}^{-1}$ dominated by the light REEs: La (1.1 $\mathrm{mg} \mathrm{g}^{-}$

$\left.{ }^{1}\right), \mathrm{Nd}\left(0.7 \mathrm{mg} \mathrm{g}^{-1}\right), \mathrm{Ce}\left(0.35 \mathrm{mg} \mathrm{g}^{-1}\right)$, and $\operatorname{Pr}\left(0.22 \mathrm{mg} \mathrm{g}^{-1}\right)$. The values for Al were also high ( $\left.4.4 \mathrm{mg} \mathrm{g}^{-1}\right)$ and could be related to previously published data: Chour et al. found concentrations between 2 to $2.5 \mathrm{mg} \mathrm{g}^{-1}$, and Liu et al. concentrations between 0.827 and $9.660 \mathrm{mg} \mathrm{g}^{-1}$ (Chour et al., 2018; Liu et al., 2019). Variability most likely occurs due to the plant growth stage at harvest (Liu et al., 2019). Other common elements found in plants were also measured, such as $\mathrm{K}$, Ca, and Mg. Manganese was also present at a low level $\left(0.91 \mathrm{mg} \mathrm{g}^{-1}\right)$. Finally, the measured $\mathrm{Si}$ concentration values in the biomass were rejected due to the formation of polymeric silicon (gel) after $\mathrm{HNO}_{3}$ digestion.

Table 1 - Concentration of various elements in the D. linearis dried biomass and in the ashed biomass $\left(550^{\circ} \mathrm{C}\right)$. SD denotes standard deviation of $\mathrm{n}=3$ replicates.

\begin{tabular}{|c|c|c|c|c|c|}
\hline & \multicolumn{2}{|c|}{$\operatorname{REEs}\left(\mathrm{mg} \mathrm{g}^{-1} \pm \mathrm{SD}\right)$} & \multicolumn{3}{|c|}{ Common and trace elements $\left(\mathrm{mg} \mathrm{g}^{-1} \pm \mathrm{SD}\right)$} \\
\hline & Biomass & Ash & & Biomass & Ash \\
\hline $\mathrm{La}$ & $1.08 \pm 0.05$ & $12.6 \pm 0.10$ & $\mathrm{Al}$ & $4.4 \pm 0.30$ & $63.9 \pm 0.10$ \\
\hline $\mathrm{Ce}$ & $0.35 \pm 0.02$ & $3.01 \pm 0.01$ & $\mathrm{Ca}$ & $1.8 \pm 0.10$ & $22.4 \pm 0.50$ \\
\hline $\operatorname{Pr}$ & $0.22 \pm 0.01$ & $2.79 \pm 0.02$ & $\mathrm{Fe}$ & $0.24 \pm 0.010$ & $3.3 \pm 0.10$ \\
\hline $\mathrm{Nd}$ & $0.70 \pm 0.04$ & $7.66 \pm 0.04$ & K & $5.0 \pm 0.10$ & $131.0 \pm 0.50$ \\
\hline $\mathrm{Sm}$ & $0.17 \pm 0.01$ & $1.37 \pm 0.01$ & $\mathrm{Mg}$ & $0.97 \pm 0.03$ & $11.46 \pm 0.02$ \\
\hline Gd & $0.07 \pm 0.01$ & $0.73 \pm 0.01$ & $\mathrm{Mn}$ & $0.91 \pm 0.05$ & $11.44 \pm 0.02$ \\
\hline Y & $0.12 \pm 0.01$ & $1.11 \pm 0.01$ & $\mathrm{Na}$ & $4.13 \pm 0.05$ & $0.4 \pm 0.01$ \\
\hline \multirow[t]{4}{*}{$\sum$ REEs } & $2.70 \pm 0.10$ & $30 \pm 0.20$ & $\mathrm{P}$ & $0.26 \pm 0.05$ & $3.3 \pm 0.04$ \\
\hline & & & $\mathrm{S}$ & $1.10 \pm 0.02$ & $8.7 \pm 0.20$ \\
\hline & & & $\mathrm{Si}$ & -* & $281 \pm 0.9$ \\
\hline & & & $\mathrm{Pb}$ & $0.14 \pm 0.03$ & $1.36 \pm 0.01$ \\
\hline
\end{tabular}


*: Indicates that proper determination was not feasible due to gel formation in the $\mathrm{HNO}_{3}$ digestate, most likely a Si polymer

Thermogravimetric analysis of D. linearis biomass (Fig. 1) shows that most of the organic matter is decomposed below $550{ }^{\circ} \mathrm{C}$, yielding a total loss of $92.3 \%$. Three distinct steps were observed and assigned to respectively: (i) evaporation of adsorbed water; (ii) combustion of cellulose and hemi-cellulose; and (iii) combustion of hemicellulose and lignin (Carrier et al., 2011; Hazotte et al., 2017). As no significant mass loss is observed above $550{ }^{\circ} \mathrm{C}$, this temperature was chosen for the production of $D$. linearis ash.

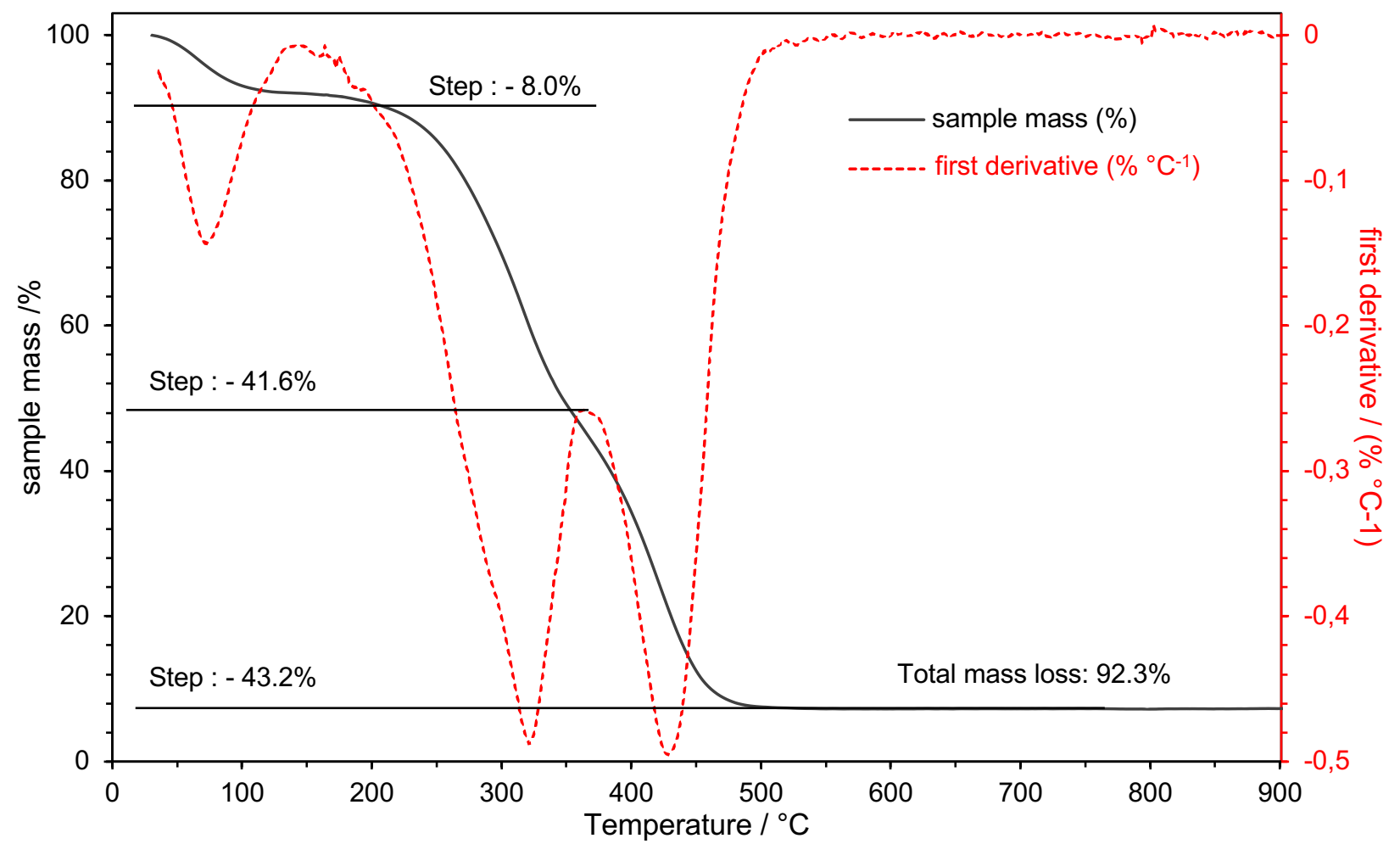

Fig. 1 - Thermogravimetric analysis of the D. linearis biomass, and the first derivative (smoothed over 50 points). 
XRD pattern analysis revealed that $D$. linearis ash produced at $550{ }^{\circ} \mathrm{C}$ was mainly amorphous (Fig. S1), as only the diffraction peak of $\mathrm{SiO}_{2}$ (quartz) could be identified. Elemental analysis of the D. linearis ash produced at $550{ }^{\circ} \mathrm{C}$ revealed that $\mathrm{Si}$ was a major constituent $(28.1 \mathrm{wt} \%)$ and the other main elements are $\mathrm{K}(13.1 \mathrm{wt} \%)$ and $\mathrm{Al}(6.4 \mathrm{wt} \%)$. When expressed on oxide basis, the three elements account for $57.5+12.6+10.5=80.6 \mathrm{wt} \%$ of the $D$. linearis ash, constituting the bulk of the material. Conversely, REEs constitute a minor fraction accounting for $3.5 \mathrm{wt} \%$ when expressed as $\mathrm{REE}_{2} \mathrm{O}_{3}$.

The ashed biomass resembles coal fly ash (CFA) produced in coal-fired power plants, in which concentrations of $\mathrm{SiO}_{2}(37-52 \mathrm{wt} \%)$ and $\mathrm{Al}_{2} \mathrm{O}_{3}(20-29 \mathrm{wt} \%)$ are comparable, although $\mathrm{Fe}_{2} \mathrm{O}_{3}$ concentrations are higher (5-24 wt\%), with composition strongly varying depending on the origin of the coal (Taggart et al., 2016). The parallel is particularly relevant as CFA is considered as a potential source of REEs in multiple studies, as concentration vary from $0.1 \mathrm{wt} \%$ to $1 \mathrm{wt} \%$ as of total REEs (Białecka and Całus-Moszko, 2013; Binnemans et al., 2015; Seredin, 1996). Similarly to $D$. linearis ash, CFA are mainly amorphous with aluminosilicate glass accounting for $70-80 \%$ of the material (King et al., 2018; Wang et al., 2019).

\subsection{Considerations for REEs extraction}

REEs speciation in ash remained unclear after XRD analysis, since no REE-bearing phase was detected. Preliminary attempts at recovering REEs were conducted by using concentrated $\mathrm{HNO}_{3}$ at $230{ }^{\circ} \mathrm{C}$ and 80 bar resulted in low recovery yields $(<50 \%)$. Such severe conditions usually yield quantitative extraction of metal minority phases. Hence, REEs are strongly bound to the aluminosilicate matrix. 
Similarly, REE extraction from CFA is challenging and usually results in low extraction yields $(<40 \%)$ when using mineral acids (e.g., $\left.\mathrm{HCl}, \mathrm{HNO}_{3}, \mathrm{H}_{2} \mathrm{SO}_{4}\right)$ (Kashiwakura et al., 2013; King et al., 2018; Taggart et al., 2016; Tang et al., 2019). Even though the conditions for the production of the ash differs from coal to hyperaccumulator biomass, the resulting product and concomitant difficulties in REEs extraction are comparable. In the case of CFA, extraction is made difficult because REEs are dispersed throughout the aluminosilicate glass phase (Hower et al., 2013; Kolker et al., 2017). Consequently, it is inferred that REEs are dispersed throughout the aluminosilicate glass matrix of $D$. linearis ash. In the light of these considerations, a flowsheet for REEs extraction is proposed (Fig. 2).

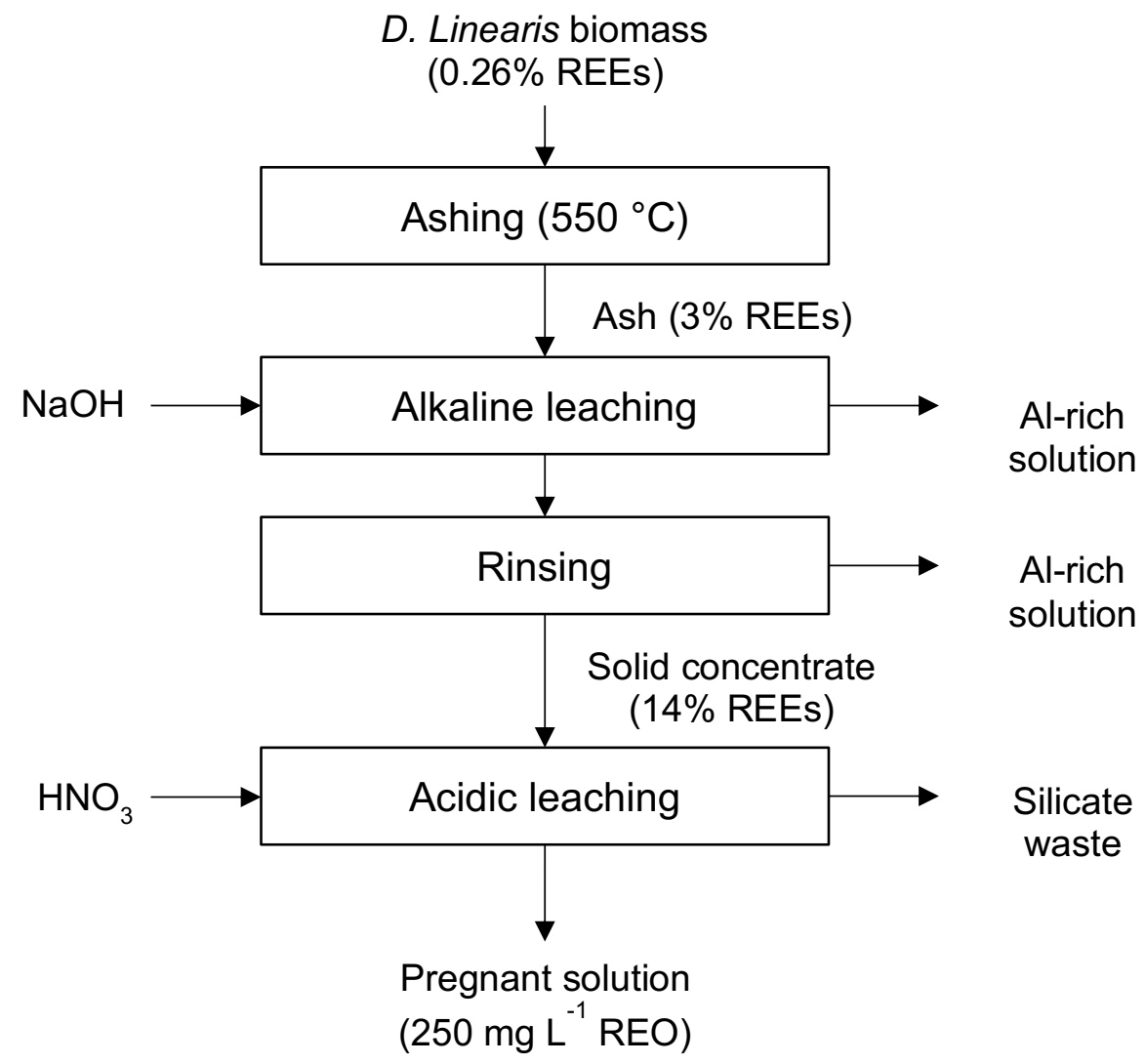

Fig. 2 - Proposed flowsheet for the recovery of REEs from D. linearis ash. 


\subsection{Alkaline leaching}

The aim of the alkaline leaching step is double: destroying the aluminosilicate glass matrix to render REEs available for extraction and removing as much as possible aluminum. It is inspired by the Bayer process as both $\mathrm{Al}$ and $\mathrm{Si}$ are soluble in heated concentrated $\mathrm{NaOH}$ solution, $\mathrm{Al}$ being soluble mainly as $\mathrm{NaAlO}_{2(\mathrm{aq})}$ and $\mathrm{Si}$ as $\mathrm{Na}_{2} \mathrm{SiO}_{3(\mathrm{aq})}$ (Ostap, 1986). Released REEs are expected to immediately precipitate as either hydroxide or carbonate. Because the ash material is different from traditionally processed bauxite, initial tests were conducted to control the solubility of $\mathrm{Al}$ and $\mathrm{Si}$ using temperatures ranging from 20 to $80{ }^{\circ} \mathrm{C}$ and $\mathrm{NaOH}$ concentrations from 1 to $5 \mathrm{M}$.

\subsubsection{Parametrical studies}

After three hours, the extraction efficiencies or soluble fraction for Al varied little with respect to operating conditions (Fig. 3). The extraction rate was minimal when working at $20{ }^{\circ} \mathrm{C}$ along with $5 \mathrm{M} \mathrm{NaOH}(66 \%)$, and maximal when using $5 \mathrm{M} \mathrm{NaOH}(89 \%)$ at the maximum temperature $\left(80{ }^{\circ} \mathrm{C}\right)$. Quantitative extraction of $\mathrm{Si}$ was reached in all, but one of the experiments, when temperature was kept at $20^{\circ} \mathrm{C}$. REE concentrations in the alkali leachate were below the detection limit, ensuring that at least $95 \%$ of the REEs were not lost. Although extraction efficiencies were close to $90 \%$ under best conditions, it should be noted that a significant amount of $\mathrm{Al}$ is kept in the

solid phase along with REEs at similar concentrations: $(0.41 \pm 0.03) \times 10^{-3} \mathrm{~mol} \mathrm{~g}^{-1}$ for $\mathrm{Al}$, and $(0.42 \pm 0.09) \times 10^{-3} \mathrm{~mol} \mathrm{~g}^{-1}$ as total REEs. 

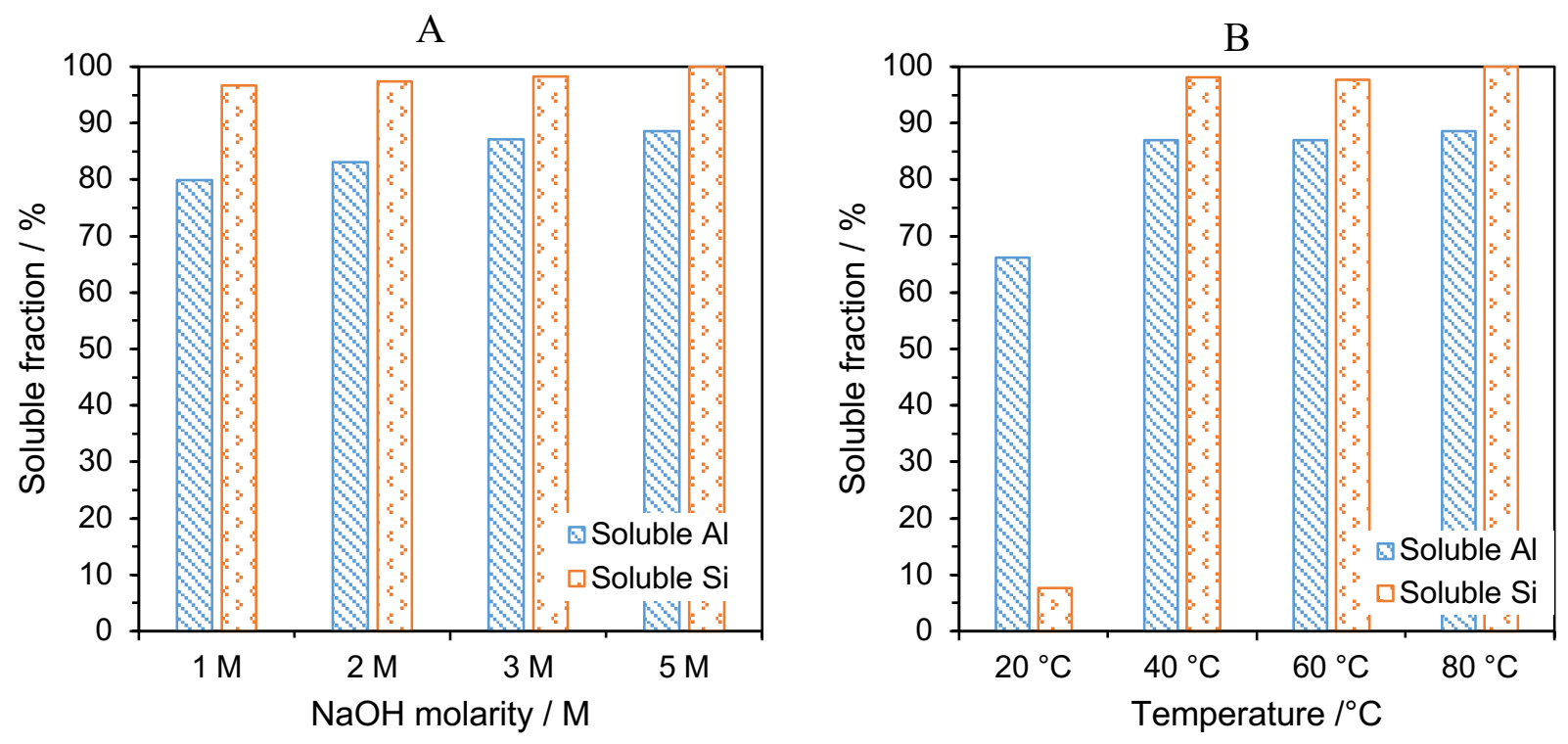

Fig. 3 - Soluble fractions of Al and Si from D. linearis ash according to operating conditions after $3 \mathrm{~h}$ of caustic soda extraction. Temperature was kept at $80^{\circ} \mathrm{C}$ in the first set of experiments (A), and $\mathrm{NaOH}$ concentration was kept at $5 \mathrm{M}$ in the second set of experiments (B).

In the alkaline leachate, REE concentrations were below detection limits, confirming the assumption that REE hydroxides or carbonates immediately precipitate subsequently to aluminosilicate matrix dissolution.

Kinetic studies have provided a better understanding of the situation as distinct behaviour has been observed (Fig. 4). At $20^{\circ} \mathrm{C}$, equilibrium may have not been reached, even after $3 \mathrm{~h}$. At other temperatures, the curves appear to converge towards a value of $89 \%$. The curves for 40 and $60{ }^{\circ} \mathrm{C}$ have similar behaviour, with extraction at $60^{\circ} \mathrm{C}$ appearing to be faster. Extraction at $80{ }^{\circ} \mathrm{C}$ proved to be rapid, while an unexpected re-precipitation of $\mathrm{Al}$ after $15 \mathrm{~min}$ occurred. The origin of the reprecipitation was not determined at that time and will be discussed in section 3.3.2.2. 


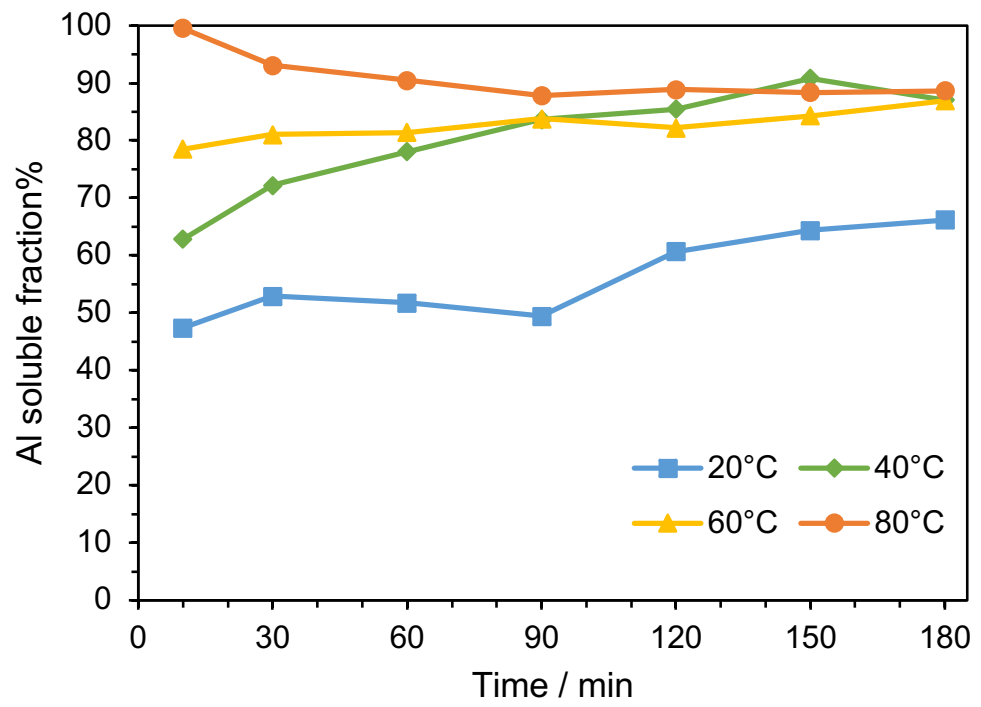

Fig. 4 - Evolution of the soluble fraction of $\mathrm{Al}$ present in the ash in $\mathrm{NaOH} 5 \mathrm{M}$ at different temperatures.

As the $\mathrm{Al}$ extraction rate was not as high as expected (below 90\%), a design of experiments was conducted with the following two objectives: (i) to continue the extraction (i.e., reach 100\%) and (ii) for this extraction rate, to use the minimal amount of $\mathrm{NaOH}$ and the lowest temperature. Previous parametric studies were used to select adequate ranges for the parameters $(\mathrm{NaOH}$ concentration, temperature and extraction time) aiming to achieve an extraction rate of $100 \%$. Extraction duration proved to be an insignificant parameter, which is consistent with previous observations above $60^{\circ} \mathrm{C}$ (Fig. 4, Table S1). Thus, Al extraction efficiency was computed using the remaining concentration in the solid. A two-factor interaction model was fitted $\left(\mathrm{R}^{2}=0.8917\right)$ to temperature and $\mathrm{NaOH}$ concentration (Equation 1, Fig. 5), with $\mathrm{X}_{\mathrm{Al}}$ the $\mathrm{Al}$ extracted fraction in $\%$, $\mathrm{T}$ in ${ }^{\circ} \mathrm{C}$ and $[\mathrm{NaOH}]$ expressed in $\mathrm{mol} \mathrm{L}^{-1}(\mathrm{M})$.

$\mathrm{X}_{\mathrm{Al}}=111.55-0.3643 \times \mathrm{T}-5.013 \times[\mathrm{NaOH}]+0.0748 \times \mathrm{T} \times[\mathrm{NaOH}]$

(Equation 1) 
Al extraction efficiency increased with increasing temperature and soda solution molarity; however, $100 \%$ extraction rate could not be achieved within the design space.

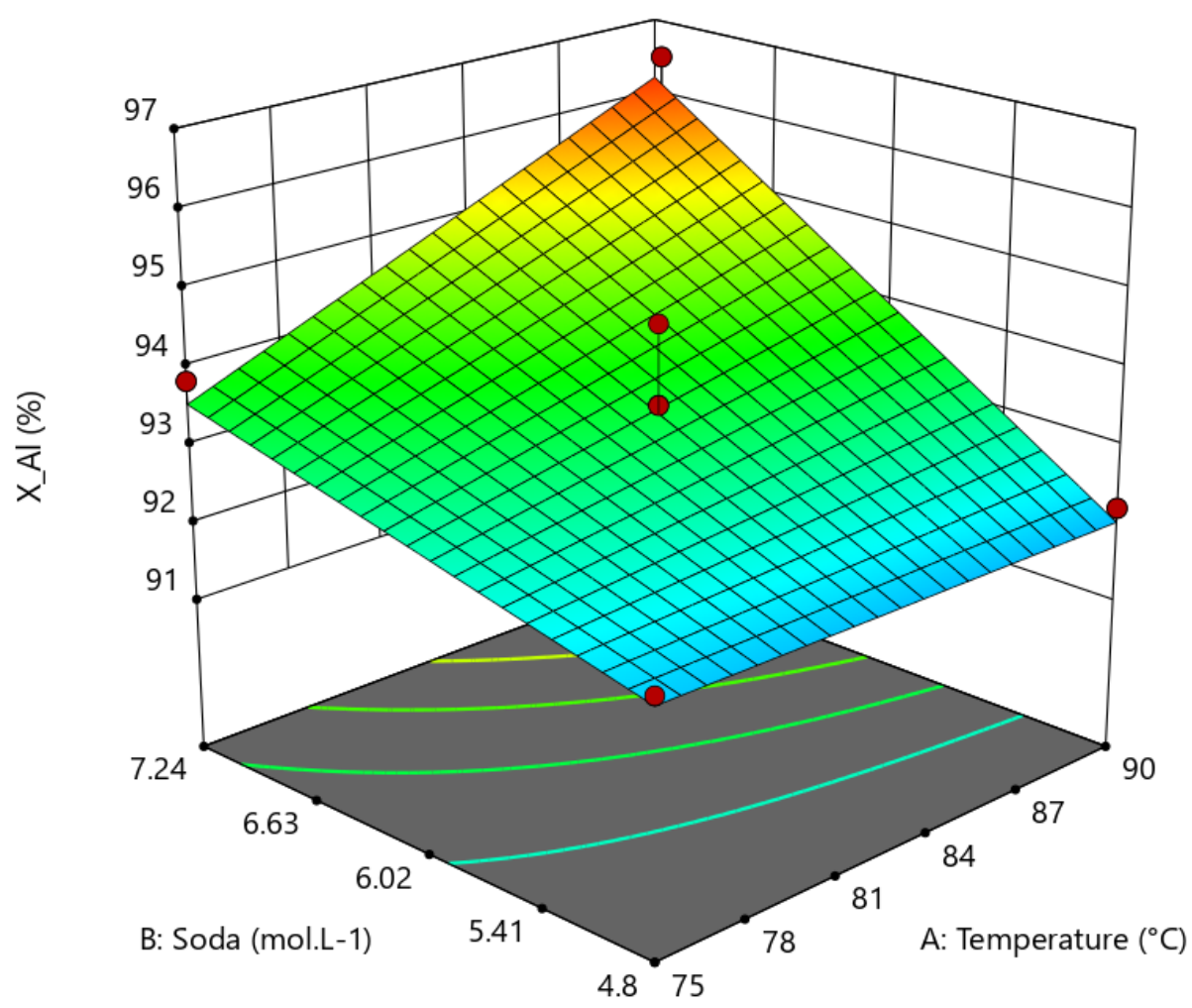

Fig. 5 - Surface representation of the two-factor interactions model for Al extraction efficiency from D. linearis ash at $5 \mathrm{~g} \mathrm{~L}^{-1}$, extraction time is not a significant parameter.

As mentioned in the Introduction, the quantitative removal of Al is desirable because it is commonly present as a trivalent cation similarly to REEs and may interfere with REE purification steps. In the following section, our objective is to better understand why Al cannot be entirely removed from the ash by a single leaching step. 


\subsubsection{Main limitation for Al removal}

A relevant strategy would be firstly to determine Al speciation in the solid, which is commonly done by examining XRD patterns, and secondly adopt a strategy to dissolve the main Al bearing phase. However, the absence of diffraction peaks in the corresponding analysis (Fig. S1), related to poor crystallinity, prevents such a strategy. Thus, it is chosen to infer Al speciation in the ash and use a model to predict Al solubility.

CHESS software was used to calculate the equilibrium speciation of a $200 \mathrm{~mL}$ solution $\left(60^{\circ} \mathrm{C}\right)$, of $1 \mathrm{M} \mathrm{NaOH}$, containing the same quantity of $\mathrm{Al}$ as is present in $1 \mathrm{~g}$ of ash $\left(2.4 \times 10^{-3} \mathrm{~mol}\right)$ as $\mathrm{Al}$ hydroxide (Diaspore). Under these conditions, the Al completely dissolves into the solution, mainly

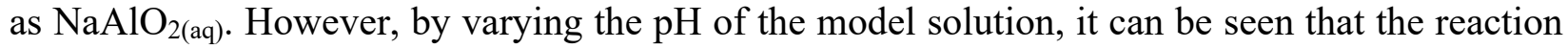
is strongly dependent on the $\mathrm{pH}$ around the operating point (Fig. 6).

By considering the actual $\mathrm{pH}$ instead of the $\mathrm{NaOH}$ concentration alone, other species that could consume the hydroxide anions, such as silica, or the undesirable absorption of atmospheric carbon dioxide, are taken into account. Here, it is assumed that the $\mathrm{pH}$ of the $\mathrm{NaOH}$ solution is below 14 due to the reaction of these other species. 


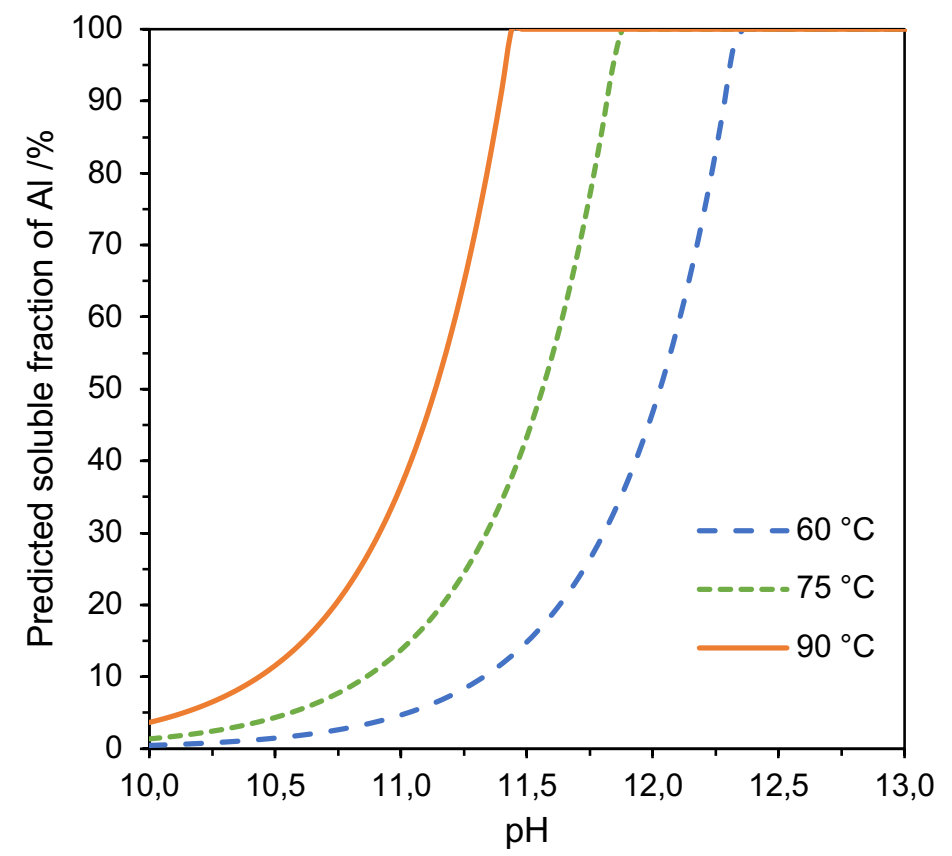

Fig. 6 - Predicted soluble fraction of $\mathrm{Al}$ in solution as a function of $\mathrm{pH}$ at different temperatures. The initial input quantity of $\mathrm{Al}$ corresponds to the quantity of ash at $5 \mathrm{~g} \mathrm{~L}^{-1}$.

Regarding $\mathrm{SiO}_{2}$, this species would consume soda forming $\mathrm{NaSiO}_{3}$ or $\mathrm{Na}_{2} \mathrm{SiO}_{4}$, resulting in a loss of alkalinity and a decrease in $\mathrm{pH}$. However, the stoichiometric excess of $\mathrm{NaOH}$ (at least $1 \mathrm{M}$ ) over the known concentration of $\mathrm{SiO}_{2}$ (only $41 \mathrm{mM}$ ) should be sufficient to maintain high alkalinity.

As for the other elements present in the ash, they should be present in alkaline form after ashing ( $\mathrm{K}$ is most likely present as $\mathrm{KOH}$ or $\mathrm{K}_{2} \mathrm{CO}_{3}$, and the same is true for $\mathrm{Ca}$ and $\mathrm{Mg}$, the other major constituents of the ash). Therefore, the presence of these compounds should not reduce alkalinity. 


\subsubsection{Effect of atmospheric $\mathrm{CO}_{2}$ absorption}

The atmospheric absorption of $\mathrm{CO}_{2}$ was lastly considered to explain the decrease in alkalinity of the solution. Indeed, a hot $\mathrm{NaOH}$ solution $\left(>60^{\circ} \mathrm{C}\right)$, continuously stirred, is likely to absorb $\mathrm{CO}_{2}$ rapidly. The $\mathrm{CO}_{2}$ is then converted to $\mathrm{CO}_{3}{ }^{2-}$, consuming two $\mathrm{HO}^{-}$(Equation 2).

$\mathrm{CO}_{2(\mathrm{~g})}+2 \mathrm{HO}_{(\mathrm{aq})}^{-} \rightarrow \mathrm{CO}_{3(\mathrm{aq})}^{2-}+\mathrm{H}_{2} \mathrm{O}$

(Equation 2)

Absorption of $\mathrm{CO}_{2}$ will decrease the $\mathrm{pH}$ of the solution as $\mathrm{CO}_{3}{ }^{2-}$ accumulates. Indeed, the $\mathrm{pKa}$ of the $\mathrm{HCO}_{3} / \mathrm{CO}_{3}{ }^{2-}$ couple is 10.13 at $60{ }^{\circ} \mathrm{C}$ (Rumble, 2019). Therefore, we hypothesize that $\mathrm{CO}_{2}$ absorption during the experiment is responsible for the loss of alkalinity of the solution, preventing the complete dissolution of Al. To test this hypothesis, the alkaline leaching experiments were conducted in a $\mathrm{CO}_{2}$-free environment, by bubbling $\mathrm{N}_{2}$ through the reaction medium and compared to control experiments by bubbling air.

When the experiments were carried out in a $\mathrm{CO}_{2}$-free environment under the same conditions, the concentration of residual solid Al was not significantly different to that of the control $((29.0 \pm$ 1.2) $\mathrm{mg} \mathrm{g}^{-1},(30.0 \pm 1.7) \mathrm{mg} \mathrm{g}^{-1}$ respectively), and Mn aside, the same went for all other analysed elements (Table S2). Hence, $\mathrm{CO}_{2}$ absorption is not the limiting parameter for Al removal. The only significant difference in contents was only observed for $\mathrm{Mn}$ : $(35.0 \pm 0.8) \mathrm{mg} \mathrm{g}^{-1}$ after extraction in bubbling air, versus $(51.0 \pm 0.3) \mathrm{mg} \mathrm{g}^{-1}$ in the $\mathrm{CO}_{2}$-free experiment. This result was consistent with the fact that leachate had a slight pink coloration under anaerobic conditions and was colourless when air was bubbled. It is likely that air, through the action of dissolved $\mathrm{O}_{2}$, favoured the oxidation of soluble $\mathrm{Mn}$ and led to the precipitation of $\mathrm{MnO}_{2}$. 


\subsubsection{Precipitation of insoluble compounds}

Since the limitation of $\mathrm{CO}_{2}$ absorption had no significant effect, we suspected the formation of an insoluble compound, an $\mathrm{Al}$ bearing phase, during the reaction. In Bayer liquors and in the presence of reactive silica, side reactions take place between soluble $\mathrm{Si}, \mathrm{Na}$, and $\mathrm{Al}$ forming insoluble sodium aluminosilicates.

These products were studied due to scale formation in heat exchangers. The main phases identified being sodalite and cancrinite $\left(\mathrm{Na}_{8}\left[\mathrm{AlSiO}_{4}\right]_{6} \mathrm{X}_{2} \cdot \mathrm{nH}_{2} \mathrm{O}, \mathrm{X}=1 / 2 \mathrm{CO}_{3}{ }^{2-}, 1 / 2 \mathrm{SO}_{4}{ }^{2-}, \mathrm{Cl}^{-}, \mathrm{OH}^{-}\right)$, with cancrinite forming at higher temperatures $\left(>120^{\circ} \mathrm{C}\right.$ ) (Armstrong, 1999; Barnes et al., 1999; Hind et al., 1999). The formation of such products consumes reactive soda and reduces the efficiency of the process. One approach to removing Si from pregnant liquor, and thus solving scaling problems, is to willingly precipitate $\mathrm{Si}$ compounds during bauxite digestion, increasing the residence time (Ostap, 1986). The aluminosilicate compounds formed are called desilication products (DSP). In this case, the Al losses as DSP are not regarded as a real loss, as the soluble Si originates from clays (e.g., kaolinite $\mathrm{Al}_{2} \mathrm{Si}_{2} \mathrm{O}_{5}(\mathrm{OH})_{4}$ ) extracted in small proportions along with the bauxite, which contains stoichiometric proportions of $\mathrm{Al}$ (Ostap, 1986). In addition to sodalite and cancrinite, DSP include the linde aluminosilicates type $\mathrm{A}$ and $\mathrm{N}$ zeolite, both of which exhibit $\mathrm{Na}_{12}\left[\mathrm{Al}_{12} \mathrm{Si}_{12} \mathrm{O}_{48}\right] \cdot 27 \mathrm{H}_{2} \mathrm{O}$ stoichiometry (Peng et al., 2018a; Peng and Vaughan, 2018). It should also be noted that their mechanism of formation includes the intermediate precipitation of an amorphous aggregate that progressively dissolves to form crystalline DSPs (Peng et al., 2018b).

Since the alkaline leachate from $D$. linearis ash is rich in $\mathrm{Si}$, the formation of analogous sodium aluminosilicate compounds is suspected. Additionally, $\mathrm{Ca}(\mathrm{OH})_{2}$ is often used to precipitate $\mathrm{Ca}_{3} \mathrm{Al}_{2}\left(\mathrm{SiO}_{4}\right)_{\mathrm{n}}(\mathrm{OH})_{(12-4 \mathrm{n})}$ to remove $\mathrm{Si}$ from Bayer liquors (Whittington, 1996), Ca being another constituent of the ash $(2.2 \mathrm{wt} \%)$ calcium aluminosilicates are also likely to precipitate. 
Regarding other studies, an analogous process was employed by Li et al. (2014) to extract $\mathrm{Al}$ from coal fly ash, using concentrated $\mathrm{NaOH}(40 \mathrm{wt} \%)$ in hydrothermal conditions $\left(230-260{ }^{\circ} \mathrm{C}\right)$. As mentioned previously, CFA is relatable to some extent to D. linearis ash. In their study, they found that the formation of a zeolitic compound $\left(1.33 \mathrm{Na}_{2} \mathrm{O} \cdot 0.67 \mathrm{CaO} \cdot \mathrm{Al}_{2} \mathrm{O}_{3} \cdot 2 \mathrm{SiO}_{2} \cdot \mathrm{H}_{2} \mathrm{O}\right)$ limited the aluminum removal rate to $91 \%$. Though CFA is richer in $\mathrm{Al}_{2} \mathrm{O}_{3}$ than D. linearis ash, the achieved removal rate is comparable to our results. Similar results were obtained by Yang et al., achieving an extraction efficiency of $92 \%$ using $45 \mathrm{wt} \% \mathrm{NaOH}$ on $\mathrm{CFA}$ at $280{ }^{\circ} \mathrm{C}$ (Yang et al., 2014). These findings reinforce our assumption of the formation of an amorphous alkali aluminosilicate. Finally, precipitation of a compound of this type would explain the decrease of Al soluble fraction observed shortly after the beginning of the dissolution step (Fig. 4).

\subsection{Rinsing}

Preliminary experiments suggested that rinsing the D. linearis ash with deionized water after alkaline leaching significantly reduced not only the soda content but also $\mathrm{Al}$ and Si content (data not shown). The rinsing experiments were conducted in column in an attempt to determine the minimal amount of water required for this step. Conductivity and $\mathrm{pH}$ reached a steady state after elution of 16 bed volumes (BV) (Fig. 7), with the solid remaining moderately alkaline with a final value of $\mathrm{pH}$ 11.2, after elution of $30 \mathrm{BV}$. 


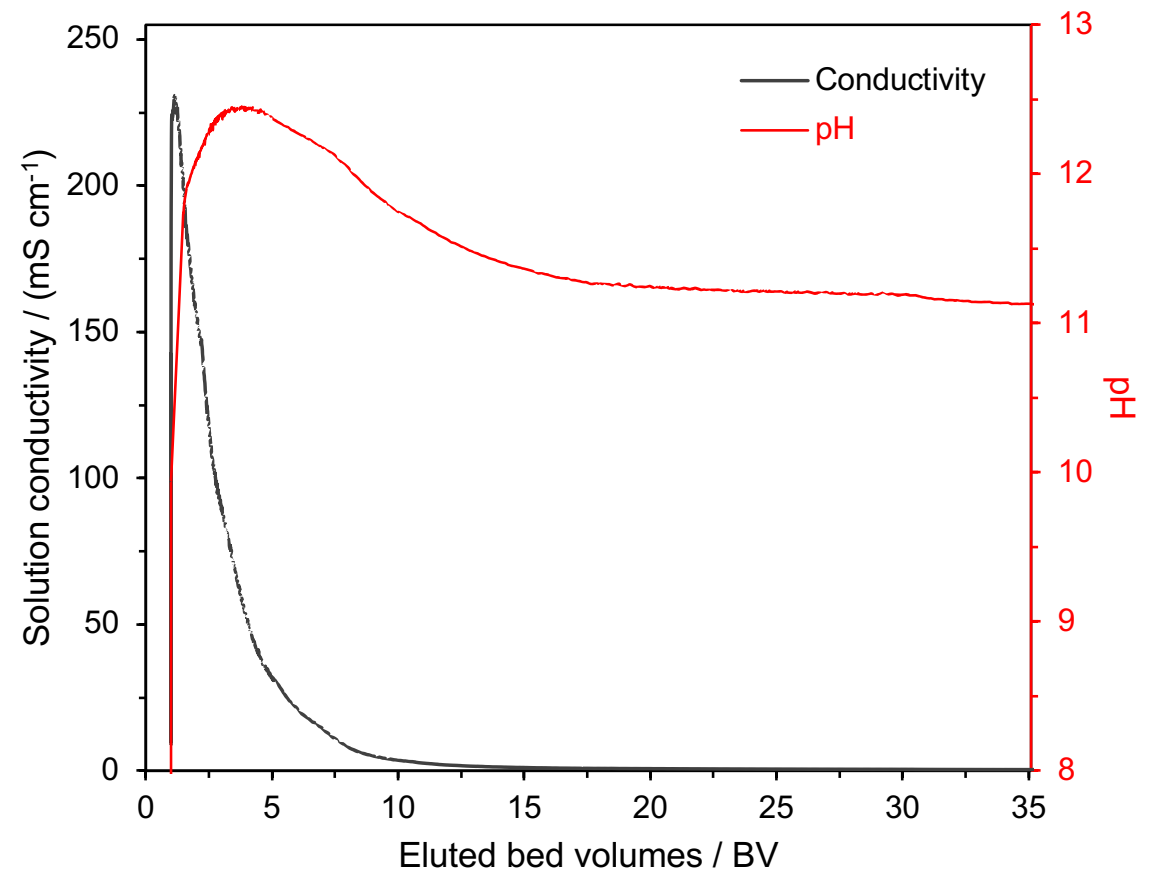

Fig. 7 - Evolution of the conductivity and $\mathrm{pH}$ of the output rinsing solution

Relatively large requirements of rinsing water $(16 \mathrm{BV})$ were necessary to stabilize the $\mathrm{pH}$ of the output solution. Thus, a leaching behaviour was suspected along with rinsing. Composition of the eluate have led to a better understanding of the rinsing step (Fig. 8). Lead, Fe, and Zn, concentrations sharply decreased and quickly fell below the detection limit, reflecting a rinsing behaviour for these impurities. Conversely, the rinsing step could be considered as water leaching, as many elements are progressively leached out with $\mathrm{Na}, \mathrm{Al}$, Si and $\mathrm{K}$ over numerous BVs. Finally, Ca leaching behaviour is consistent with the hypothesis that a Ca-aluminosilicate was formed earlier, as constant amounts were leached during the rinsing procedure for the 9 first eluted BVs. As the $\mathrm{pH}$ decreased, the Ca concentration at the column output increased. REEs were not detected in the leached solution. 

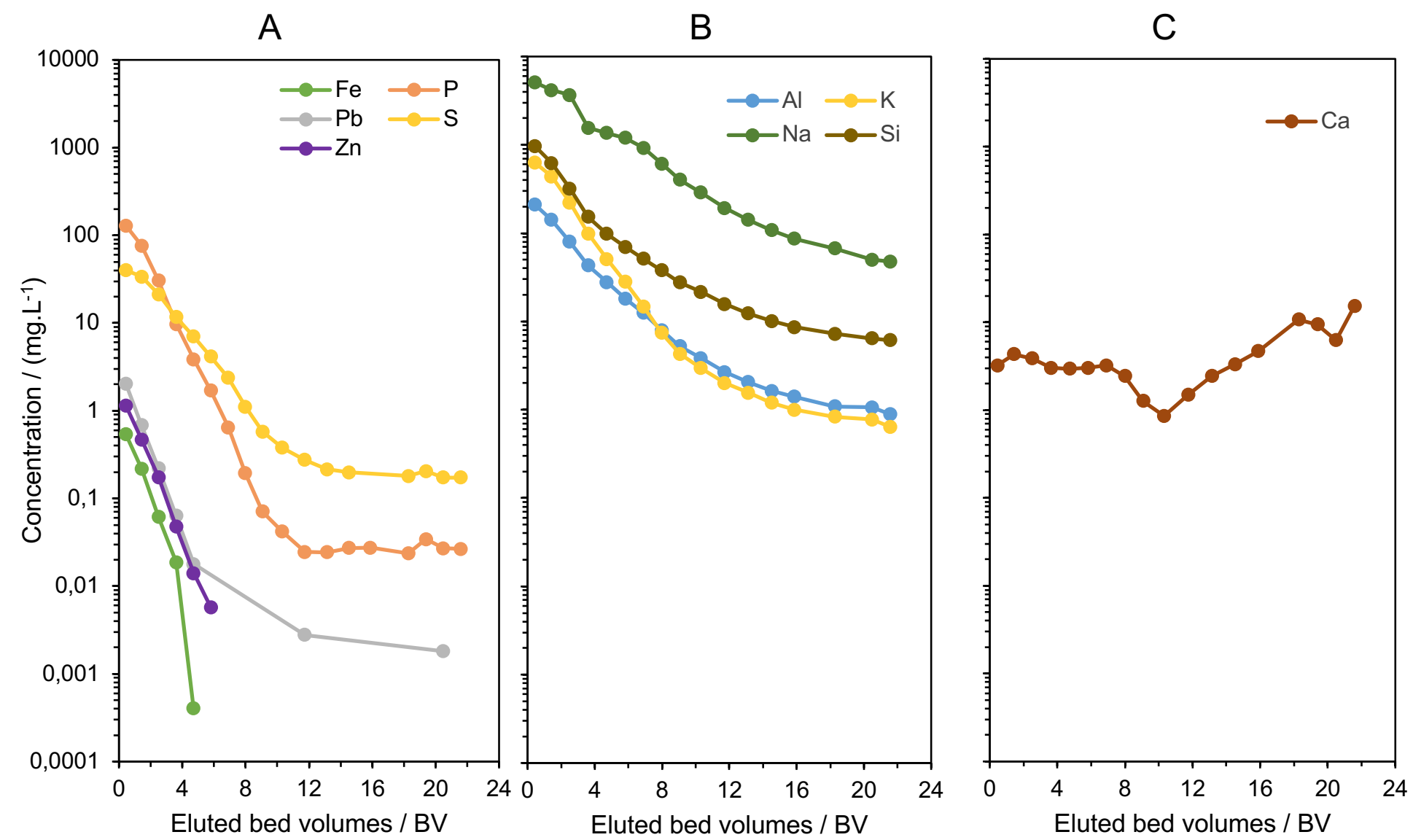

Fig. 8 - Elemental composition of the leached solution. Concentrations $\left(\mathrm{mg} \mathrm{L}^{-1}\right)$ are represented in log-scale, (A) quickly rinsed elements, (B) progressively eluted elements, and atypical $\mathrm{Ca}$ behaviour (C). REE concentrations were below detection limits in all samples $\left(0.01 \mathrm{mg} \mathrm{L}^{-1}\right)$.

\subsection{Dissolution}

The gradual dissolution of various elements was observable as the $\mathrm{pH}$ decreased (Fig. 9). The REEs behaved consistently, with the exception of cerium (Ce), due to valency states. The REEs started to appear in solution around $\mathrm{pH} 6$ and were only fully dissolved at $\mathrm{pH} 2$. Uncertainties in the initial composition of the solid cause experimental error leading to extraction efficiency values above 
$100 \%$. For Ce, dissolution occurred at a lower $\mathrm{pH}$, and was only partial at $\mathrm{pH} 2$. This discrepancy can be explained by its additional redox state $(+\mathrm{IV})$. Indeed, $\mathrm{CeO}_{2}$ is readily formed in aqueous solution and is insoluble (Gupta and Krishnamurthy, 2005). In addition, $\mathrm{HNO}_{3}$, used in this experiment, is known for its oxidizing properties, which would favour the predominance of $\mathrm{Ce}$ $(+\mathrm{IV})$.

Regarding other elements, $\mathrm{Al}$ dissolution started to occur under more acidic conditions than REEs (pH 4.2), and $77 \%$ of the introduced $\mathrm{Al}$ was finally dissolved at $\mathrm{pH} 2$. The elements $\mathrm{Ca}$ and $\mathrm{Mg}$ were expectably released into solution. Mass balances revealed that Mg was fully dissolved ( $100 \%$ soluble fraction at $\mathrm{pH} 2)$, and only a fraction of the initial $\mathrm{Ca}$ content was released $(>60 \%)$. The partial dissolution of $\mathrm{Ca}$ and $\mathrm{Al}$ at $\mathrm{pH} 2$ supports the hypothesis that $\mathrm{Ca}$ formed an insoluble compound, such as Ca-aluminosilicate.
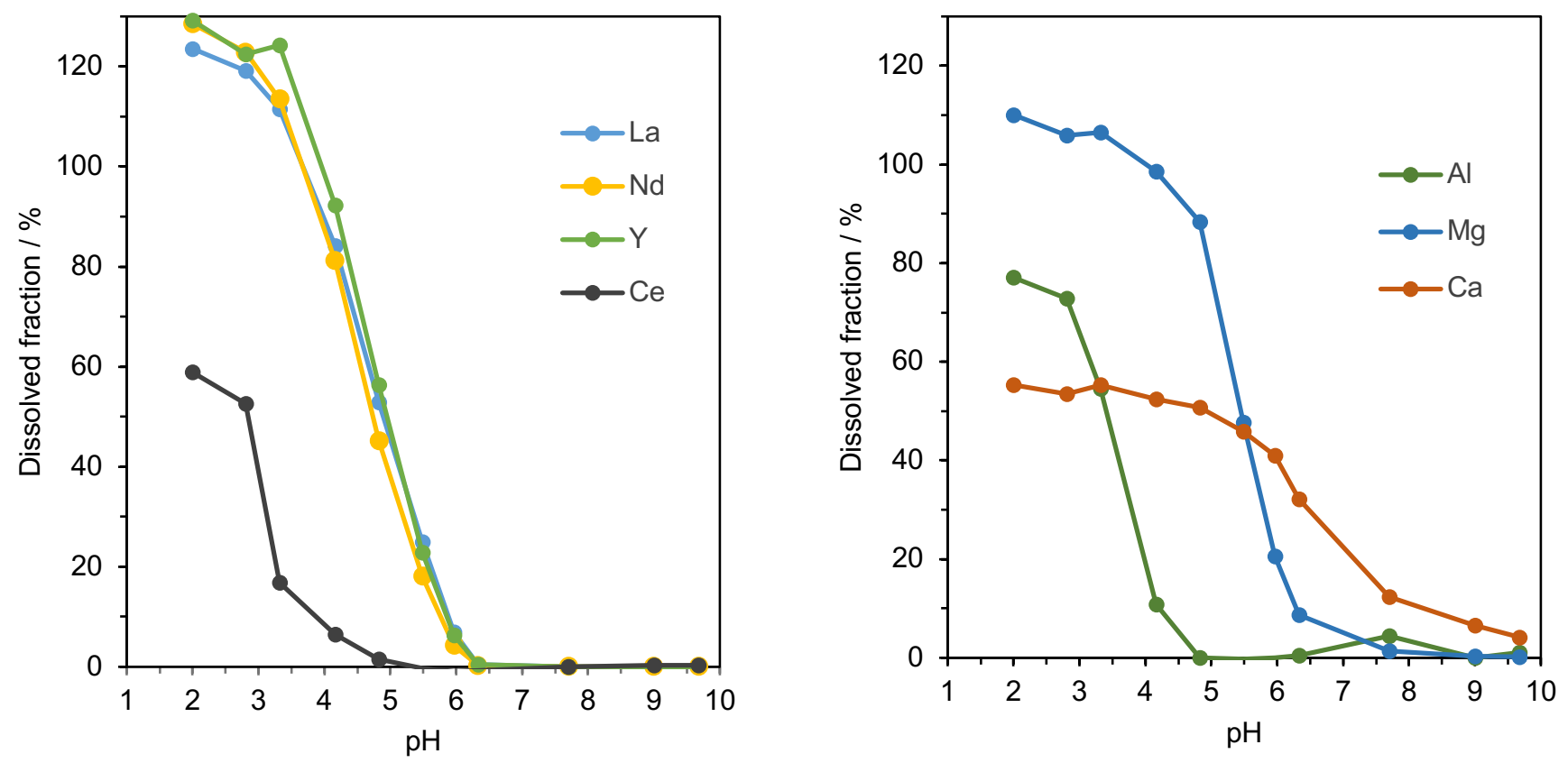

Fig. 9 - Solubilization of the main elements from the treated ash suspension with decreasing $\mathrm{pH}$. Dissolved fractions (in\%) were computed by mass balance calculations: using treated ash 
composition, aqueous concentrations, volume of the suspension and the mass of treated ash introduced.

In addition, it has been observed that at $\mathrm{pH} 4.8,50 \%$ of the REEs are dissolved while there is no $\mathrm{Al}$ in solution. In the mining industry, this property is known in reverse: precipitation of $\mathrm{Al}$ is carried out at a $\mathrm{pH}$ of 3-4 from the acidic REE stream, before precipitation of REE is carried out with ammonium carbonate at a pH of about 4-5 (Chi et al., 2003; Luo et al., 2015). In our case, the solution is neutral and the aluminum is already solid, so selective dissolution of REEs is an attractive option above $\mathrm{pH}$ 4.8. A series of dissolution at constant $\mathrm{pH}$ could be designed, with each stage extracting $60 \%$ of the REEs. That way, $99 \%$ of the REEs could be dissolved in only 5 stages, while no $\mathrm{Al}$ is dissolved. Divalent cations, such as $\mathrm{Mg}^{2+}$ and $\mathrm{Ca}^{2+}$, can be easily separated from the REE downstream (e.g., using ion exchange resin) and should not be of concern (Chour et al., 2018). However, it is inferred that slow kinetics and high-volume requirements may be the limiting parameters that need to be further investigated.

In conclusion, the final concentration of REE was $0.250 \mathrm{~g} \mathrm{~L}^{-1}$ of REE in the solution at $\mathrm{pH} 4.8$. It is assumed that industrial concentrations, typically 1 to $6 \mathrm{~g} \mathrm{~L}^{-1}$ (Schulze et al., 2017) can be achieved by increasing the solid/liquid ratio $\left(2.5 \mathrm{~g} \mathrm{~L}^{-1}\right.$ in our experiment being relatively low) or by evaporation. 


\subsection{Overall efficiency}

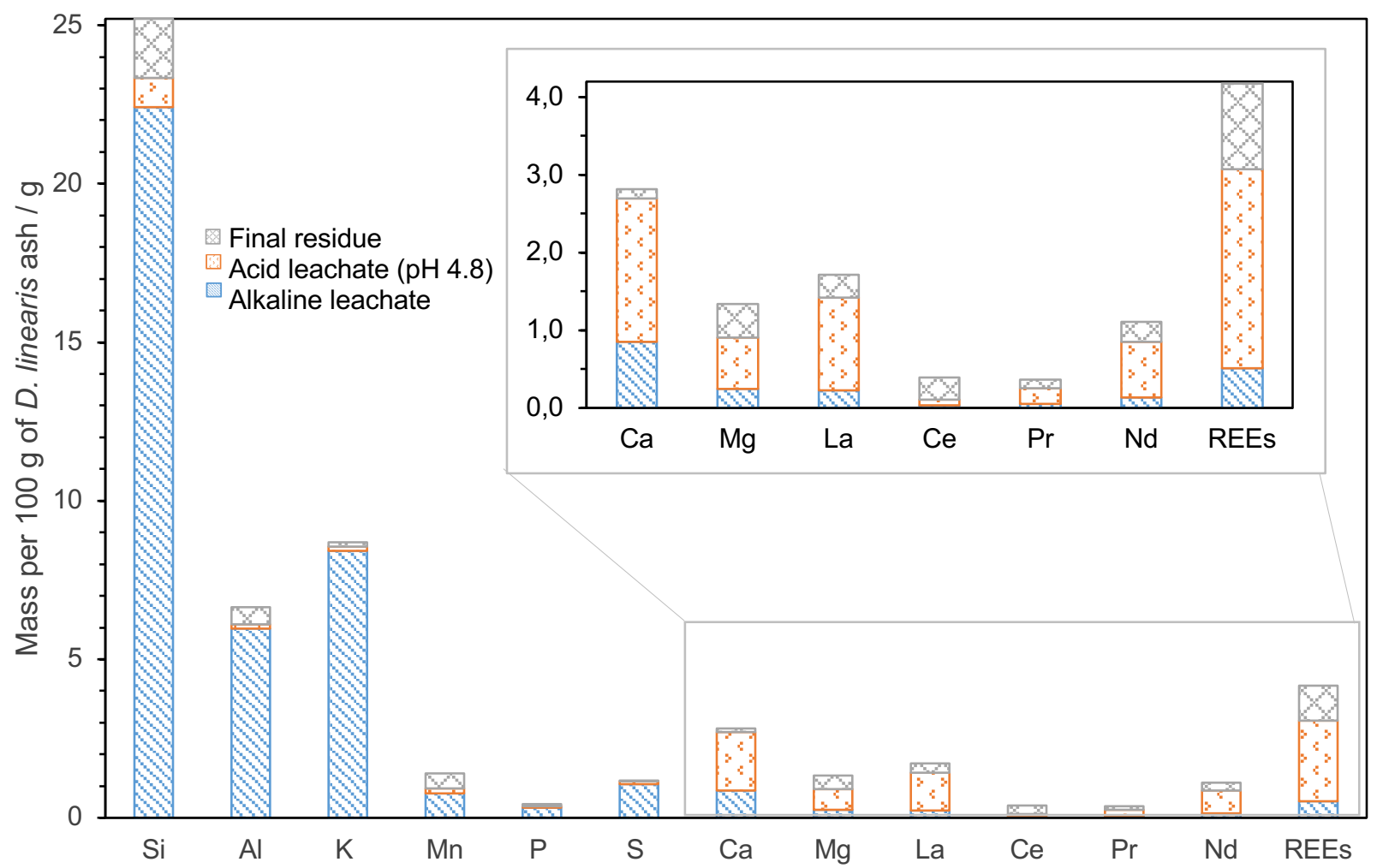

Fig. 10 - Global mass balance of elements of $D$. linearis ash shared in the steps of the process. Values stand for $100 \mathrm{~g}$ of ash. The total amounts correspond to the total initial concentrations in the ash. Refer to Table S3 for full data.

Some REEs are lost during the alkaline leaching step, however it remains unsure if REEs were actually lost in solution, or in the rinsing step, or if manipulation of small quantities of solid generated sample loss equivalent to $12 \%$. Wang et al. used a combination of alkaline leaching followed by $\mathrm{HCl}$ extraction to recover REEs from CFA (Wang et al., 2019), though they used more aggressive conditions $\left(80-150{ }^{\circ} \mathrm{C}, \mathrm{NaOH} 20-40 \%\right)$ and observed the flocculation of colloidal $\mathrm{REE}(\mathrm{OH})_{3}$ leading to unexpected mass losses. Colloidal REEs may not have been detected in the 
current study because aliquots for analysis were filtered using $0.45 \mu \mathrm{m}$ filters, whereas the bulk separation of the liquid phase was conducted using filters with larger pores $(8 \mu \mathrm{m})$.

REEs loss also occurred in the $\mathrm{HNO}_{3}$ leaching step (around 30\%) as a result of the compromise between REE recovery and keeping Al in the solid phase. In regard to the available literature, King et al (2018) used a similar approach consisting of sequential alkaline-acid leaching, subsequently using $\mathrm{NaOH}\left(6.25 \mathrm{M}, 85^{\circ} \mathrm{C}\right)$ and $\mathrm{HCl}(20 \% \mathrm{HCl})$, for the recovery of REEs from CFA (King et al., 2018). Depending on the origin of coal, and thus CFA composition, comparable extraction yields were obtained (45-75\%). The previously mentioned process discussed by Wang et al. resulted in higher extraction yields (averaging 85\%), although more aggressive conditions were used $\left(\mathrm{NaOH} 20-40 \mathrm{wt} \%, 90-150{ }^{\circ} \mathrm{C}\right.$, followed by $\mathrm{HCl}$ extraction, $4-8 \mathrm{M}$ at $40-80{ }^{\circ} \mathrm{C}$ during $2-6 \mathrm{~h}$ ) (Wang et al., 2019). In contrast, our study demonstrated that mildly acidic $\mathrm{pH}$ (4.8) obtained with $\mathrm{HNO}_{3}$ was sufficient to leach the majority of extractable REEs as overall efficiency of REEs extraction is $74 \%$ for REEs, and $78 \%$ for all REEs except Ce. Non-recovery of all of the Ce is a limited issue, as other REEs present in the hyperaccumulator ash have significantly higher economic value (e.g., Nd, Pr) (Machacek and Kalvig, 2016).

\section{Conclusions}

A novel approach for the recovery of REEs from an hyperaccumulator plant $D$. linearis has been designed. The recovery of REE from the ash was proven to be feasible, although in contrast to other process treating hyperaccumulator ash, it requires a pre-treatment step (i.e., alkaline leaching), prior to the traditional acid leaching. The conditions of the pre-treatment step were investigated and provided a better understanding of the operation by determining the limiting parameters, 
thereby enabling future scale-up and optimization. The use of mild conditions in the REE dissolution step (diluted $\mathrm{HNO}_{3}$ at ambient temperature) has resulted in satisfactory yields and is a positive increment towards greener chemistry. Nonetheless, optimization, including recycling of the soda solution, and aluminum recovery, are still needed. Further separations, leading to pure or semi-pure REE compounds, are already ongoing using current data. This study adds the possibility of using ash instead of dried biomass for the recovery of REEs from D. linearis, which has several inherent benefits, such as heat production and drastic ore enrichment. Additionally, the ash can be produced locally with little investment.

Nevertheless, analysis of environmental impact of the whole process (e.g., a life cycle assessment) is desirable, as well as an economic analysis before upscaling to project costs and process bottlenecks. Based on D. linearis biomass yield (approx. 12-15 $\mathrm{t} \mathrm{ha}^{-1}$ ), REE yields would reach 24-30 $\mathrm{kg}_{\text {REEs }} \mathrm{ha}^{-1}$ (Li et al., 2013; Liu et al., 2020). Assuming the oxide can be produced this way, the total income (which greatly depends on the current $\mathrm{Nd}$ price and biomass $\mathrm{Nd}$ concentrations) could reach 260-660 USD ha-1 ${ }^{-1}$ At present, $\mathrm{NaOH}$ costs in the alkaline leaching step render the whole process unprofitable, at least at the laboratory scale. Further studies are required to decrease the consumption of this reagent. In the medium term, it is hoped that these hydrometallurgical advances will benefit the phytoremediation of mine tailings in Southern China.

\section{Acknowledgements}

The authors wish to thank the CNRS and the University of Lorraine, the International Joint Lab ECOLAND for supporting this work, as well as Sun Yat-sen University (SYSU) through the 111 project. The authors also thank Bro-Penny (Lebanon) for its financial support. Labex Ressources 21 
and Institut Carnot ICEEL are also acknowledged for their financial support. The authors wish to thank the GISFI platform and technical staff for the pre-processing of the plant biomass, and Liu Wenshen (SYSU) for supplying the plant biomass. Are also acknowledged Steve Pontvianne and Emilien Girot (LRGP, CNRS-Univ. Lorraine), Renaud Gley and Isabelle Bihannic (LIEC, CNRS-

Univ. Lorraine). They also extend their thanks to Dr Antony van der Ent (University of Queensland, Australia) for improvement of the text.

\section{References}

Armstrong, J.A., 1999. The investigation of scale formation in the Bayer process (MSc thesis). Loughborough University, Loughborough, UK.

Baker, A.J.M., McGrath, S.P., Reeves, R.D., Smith, J.A.C., 2000. Metal hyperaccumulator plants: a review of the ecology and physiology of biological resource for phytoremediation of Metal-Polluted Soils, in: Terry, N., Bañuelos, G. (Eds.), Phytoremediation of Contaminated Soil and Water. CRC Press, Boca Raton, pp. 85-107.

Barbaroux, R., Plasari, E., Mercier, G., Simonnot, M.O., Morel, J.L., Blais, J.F., 2012. A new process for nickel ammonium disulfate production from ash of the hyperaccumulating plant Alyssum murale. Sci. Total Environ. 423, 111-119. https://doi.org/10.1016/j.scitotenv.2012.01.063

Barnes, M.C., Addai-Mensah, J., Gerson, A.R., 1999. The mechanism of the sodalite-to-cancrinite phase transformation in synthetic spent Bayer liquor. Microporous Mesoporous Mater. 31, 287-302. https://doi.org/10.1016/S1387-1811(99)00079-7

Białecka, B., Całus-Moszko, J., 2013. Analysis of the possibilities of rare earth elements obtaining from coal and fly ash. Gospod. Surowcami Miner. - Miner. Resour. Manag. 29.

Binnemans, K., Jones, P.T., Blanpain, B., Van Gerven, T., Pontikes, Y., 2015. Towards zero-waste valorisation of rare-earth-containing industrial process residues: a critical review. J. Clean. Prod. 99, 17-38. https://doi.org/10.1016/j.jclepro.2015.02.089

Burges, A., Alkorta, I., Epelde, L., Garbisu, C., 2018. From phytoremediation of soil contaminants to phytomanagement of ecosystem services in metal contaminated sites. Int. J. Phytoremediation 20, 384-397. https://doi.org/10.1080/15226514.2017.1365340

Carrier, M., Loppinet-Serani, A., Denux, D., Lasnier, J.-M., Ham-Pichavant, F., Cansell, F., Aymonier, C., 2011. Thermogravimetric analysis as a new method to determine the lignocellulosic composition of biomass. Biomass Bioenergy 35, 298-307. https://doi.org/10.1016/j.biombioe.2010.08.067

Chen, Y.Y., Liu, W.S., Yuan, M., Guo, M.N., Liu, C., Huot, H., Tang, Y.T., Qiu, R.L., 2019. Advancement in researches on the absorption, translocation, detoxifcation and fractionation of rare earth elements in hyperaccumulators. Acta Pedol. Sin. 56, 785-795. https://doi.org/10.11766/trxb201806290190 
Chen, Z.Q., Chen, Z.B., 2020. Clipping strategy to assist phytoremediation by hyperaccumulator Dicranopteris dichotoma at rare earth mines. Int. J. Phytoremediation 1-10. https://doi.org/10.1080/15226514.2020.1725870

Chi, R., Zhou, Z., Xu, Z., Hu, Y., Zhu, G., Xu, S., 2003. Solution-chemistry analysis of ammonium bicarbonate consumption in rare-earth-element precipitation. Metall. Mater. Trans. B 34, 611-617. https://doi.org/10.1007/s11663-003-0031-z

Chour, Z., Laubie, B., Morel, J.L., Tang, Y., Qiu, R., Simonnot, M.-O., Muhr, L., 2018. Recovery of rare earth elements from Dicranopteris dichotoma by an enhanced ion exchange leaching process. Chem. Eng. Process. - Process Intensif. 130, 208-213. https://doi.org/10.1016/j.cep.2018.06.007

Chour, Z., Laubie, B., Morel, J.L., Tang, Y.T., Simonnot, M.O., Muhr, L., 2020. Basis for a new process for producing REE oxides from Dicranopteris linearis. J. Environ. Chem. Eng. 103961. https://doi.org/10.1016/j.jece.2020.103961

Connelly, N.G., Damhus, T., Hartshorn, R.M., Hutton, A., 2005. Nomenclature of inorganic chemistry. IUPAC recommendations 2005. Royal Society of Chemistry Publishing/IUPAC, Cambridge, UK.

Cundy, A.B., Bardos, R.P., Puschenreiter, M., Mench, M., Bert, V., Friesl-Hanl, W., Müller, I., Li, X.N., Weyens, N., Witters, N., Vangronsveld, J., 2016. Brownfields to green fields: Realising wider benefits from practical contaminant phytomanagement strategies. J. Environ. Manage. 184, 67-77. https://doi.org/10.1016/j.jenvman.2016.03.028

Fern, K., 2019. Dicranopteris linearis [WWW Document]. Trop. Plants Database. URL www.tropical.theferns.info/viewtropical.php?id=Dicranopteris+linearis (accessed 12.3.19).

Guo, F.Q., Wang, Y.Q., Sun, J.X., Chen, H.M., 1996. REE bound proteins in natural plant fern Dicranopteris dichotoma by INAA. J. Radioanal. Nucl. Chem. Artic. 209, 91-99. https://doi.org/10.1007/BF02063534

Gupta, C.K., Krishnamurthy, N., 2005. Extractive metallurgy of rare earths. CRC Press, Boca Raton, Fla.

Habashi, F., 2016. A Hundred Years of the Bayer Process for Alumina Production, in: Donaldson, D., Raahauge, B.E. (Eds.), Essential Readings in Light Metals. Springer International Publishing, Cham, pp. 85-93. https://doi.org/10.1007/978-3-319-48176-0_12

Hazotte, C., Laubie, B., Rees, F., Morel, J.L., Simonnot, M.O., 2017. A novel process to recover cadmium and zinc from the hyperaccumulator plant Noccaea caerulescens. Hydrometallurgy 174, 56-65. https://doi.org/10.1016/j.hydromet.2017.09.012

Hind, A.R., Bhargava, S.K., Grocott, S.C., 1999. The surface chemistry of Bayer process solids: a review. Colloids Surf. Physicochem. Eng. Asp. 146, 359-374. https://doi.org/10.1016/S0927-7757(98)00798-5

Ho, R., Teai, T., Bianchini, J.-P., Lafont, R., Raharivelomanana, P., 2011. Ferns: From Traditional Uses to Pharmaceutical Development, Chemical Identification of Active Principles, in: Kumar, A., Fernández, H., Revilla, M.A. (Eds.), Working with Ferns. Springer New York, New York, NY, pp. 321-346. https://doi.org/10.1007/978-1-4419-7162-3_23

Hower, J.C., Groppo, J.G., Joshi, P., Dai, S., Moecher, D.P., Johnston, M.N., 2013. Location of Cerium in Coal-Combustion Fly Ashes: Implications for Recovery of Lanthanides. Coal Combust. Gasif. Prod. 5, 73-78. https://doi.org/10.4177/CCGP-D-13-00007.1

Huot, H., Guo, M.N., Liu, C., Liu, W., Yuan, M., Chen, Y.Y., Zhu, S.C., Wang, Y., Wu, Y.L., Ye, P.X., Chen, J.Q., Séré, G., Watteau, F., Chao, Y.Q., Auclerc, A., Morel, J.L., Tang, Y.T., Qiu, R.L., 2018. Reclamation of ionic rare earth elements (REEs) mine tailings in Southern China, in: 11th Sino-French Workshop - Innovations for the Circular Economy by 
Recycling Secondary Resources. Presented at the 11th Sino-French Workshop Innovations for the circular Economy by Recycling Secondary Resources, Sun Yat-sen University, Guangzhou.

Kashiwakura, S., Kumagai, Y., Kubo, H., Wagatsuma, K., 2013. Dissolution of Rare Earth Elements from Coal Fly Ash Particles in a Dilute $\mathrm{H}_{2} \mathrm{SO}_{4}$ Solvent. Open J. Phys. Chem. 03, 69-75. https://doi.org/10.4236/ojpc.2013.32009

King, J.F., Taggart, R.K., Smith, R.C., Hower, J.C., Hsu-Kim, H., 2018. Aqueous acid and alkaline extraction of rare earth elements from coal combustion ash. Int. J. Coal Geol. 195, 75-83. https://doi.org/10.1016/j.coal.2018.05.009

Kolker, A., Scott, C., Hower, J.C., Vazquez, J.A., Lopano, C.L., Dai, S., 2017. Distribution of rare earth elements in coal combustion fly ash, determined by SHRIMP-RG ion microprobe. Int. J. Coal Geol. 184, 1-10. https://doi.org/10.1016/j.coal.2017.10.002

Li, H.Q., Hui, J.B., Wang, C.Y., Bao, W.J., Sun, Z.H., 2014. Extraction of alumina from coal fly ash by mixed-alkaline hydrothermal method. Hydrometallurgy 147-148, 183-187. https://doi.org/10.1016/j.hydromet.2014.05.012

Li, J.H., Gao, Yang, Gao, Yan, Chen, Z.F., Wang, R. xiang, Xu, Z.F., 2020. Study on aluminum removal through 5-sulfosalicylic acid targeting complexing and D290 resin adsorption. Miner. Eng. 147, 106175. https://doi.org/10.1016/j.mineng.2019.106175

Li, X.F., Chen, Z.B., Zheng, L.D., Zhang, X.Y., Li, R.L., 2013. Responses of Dicranopteris dichotoma growth to environmental factors in eroded red-soil region of Southern China. Bull. Soil Water Conserv. 33, 33-37. https://doi.org/10.13961/j.cnki.stbctb.2013.03.038

Liu, C., Yuan, M., Liu, W.-S., Guo, M.-N., Zheng, H.-X., Huot, H., Tang, Y.-T., Jally, B., Laubie, B., Simonnot, M.-O., Morel, J.L., Qiu, R.-L., 2020. Element Case Studies: Rare Earth Elements, in: Van der Ent, A., Echevarria, G., Baker, A.J.M., Morel, J.L. (Eds.), Agromining: Farming for Metals. Springer, Cham.

Liu, L., Wang, X.D., Wen, Q., Jia, Q.Q., Liu, Q.J., 2017. Interspecific associations of plant populations in rare earth mining wasteland in southern China. Int. Biodeterior. Biodegrad. 118, 82-88. https://doi.org/10.1016/j.ibiod.2017.01.011

Liu, W.S., Zheng, H.X., Guo, M.N., Liu, C., Huot, H., Morel, J.L., van der Ent, A., Tang, Y.T., Qiu, R.L., 2019. Co-deposition of silicon with rare earth elements (REEs) and aluminium in the fern Dicranopteris linearis from China. Plant Soil 1-11. https://doi.org/10.1007/s11104-019-04005-0

Luo, X.P., Zou, L.P., Ma, P. long, Luo, C.G., Xu, J., Tang, X.K., 2015. Removing aluminum from a low-concentration lixivium of weathered crust elution-deposited rare earth ore with neutralizing hydrolysis. Rare Met. 36, 685-690. https://doi.org/10.1007/s12598-015-06213

Machacek, E., Kalvig, P., 2016. Road map for REE material supply autonomy in Europe. Geological Survey of Denmark and Greenland (GEUS) and D’Appolonia.

Mai, N.T., Nguyen, N.H., Tsubota, T., Shinogi, Y., Dultz, S., Nguyen, M.N., 2019. Fern Dicranopteris linearis-derived biochars: Adjusting surface properties by direct processing of the silica phase. Colloids Surf. Physicochem. Eng. Asp. 583, 123937. https://doi.org/10.1016/j.colsurfa.2019.123937

Ochsenkühn-Petropoulou, M.Th., Hatzilyberis, K.S., Mendrinos, L.N., Salmas, C.E., 2002. PilotPlant Investigation of the Leaching Process for the Recovery of Scandium from Red Mud. Ind. Eng. Chem. Res. 41, 5794-5801. https://doi.org/10.1021/ie011047b

Ostap, S., 1986. Control of Silica in the Bayer Process Used for Alumina Production. Can. Metall. Q. 25, 101-106. https://doi.org/10.1179/cmq.1986.25.2.101 
Packey, D.J., Kingsnorth, D., 2016. The impact of unregulated ionic clay rare earth mining in China. Resour. Policy 48, 112-116. https://doi.org/10.1016/j.resourpol.2016.03.003

Peng, H., Ding, M.L., Vaughan, J., 2018a. The Anion Effect on Zeolite Linde Type A to Sodalite Phase Transformation. Ind. Eng. Chem. Res. 57, 10292-10302. https://doi.org/10.1021/acs.iecr.8b02026

Peng, H., Seneviratne, D., Vaughan, J., 2018b. Role of the Amorphous Phase during Sodium Aluminosilicate Precipitation. Ind. Eng. Chem. Res. 57, 1408-1416. https://doi.org/10.1021/acs.iecr.7b04538

Peng, H., Vaughan, J., 2018. Aluminate effect on desilication product phase transformation. J. Cryst. Growth 492, 84-91. https://doi.org/10.1016/j.jcrysgro.2018.04.013

Qin, B.J., Liu, W.S., He, E.K., Li, Y.Y., Liu, C., Ruan, J.J., Qiu, R.L., Tang, Y.T., 2019. Vacuum pyrolysis method for reclamation of rare earth elements from hyperaccumulator Dicranopteris dichotoma grown in contaminated soil. J. Clean. Prod. 229, 480-488. https://doi.org/10.1016/j.jclepro.2019.05.031

Rodrigues, J., Gérard, A., Séré, G., Morel, J.-L., Guimont, S., Simonnot, M.-O., Pons, M.-N., 2019. Life cycle impacts of soil construction, an innovative approach to reclaim brownfields and produce nonedible biomass. J. Clean. Prod. 211, 36-43. https://doi.org/10.1016/j.jclepro.2018.11.152

Schulze, R., Lartigue-Peyrou, F., Ding, J., Schebek, L., Buchert, M., 2017. Developing a Life Cycle Inventory for Rare Earth Oxides from Ion-Adsorption Deposits: Key Impacts and Further Research Needs. J. Sustain. Metall. 3, 753-771. https://doi.org/10.1007/s40831-017-0139$\mathrm{Z}$

Seredin, V.V., 1996. Rare earth element-bearing coals from the Russian Far East deposits. Int. J. Coal Geol. 30, 101-129. https://doi.org/10.1016/0166-5162(95)00039-9

Simonnot, M.-O., Vaughan, J., Laubie, B., 2018. Processing of Bio-ore to Products, in: Van der Ent, A., Echevarria, G., Baker, A.J.M., Morel, J.L. (Eds.), Agromining: Farming for Metals. Springer International Publishing, Cham, pp. 39-51. https://doi.org/10.1007/978-3-31961899-9 3

Srivastava, K., 2007 . Ethnobotanical studies of some important ferns. Ethnobot. Leafl. 2007, 64 172.

Taggart, R.K., Hower, J.C., Dwyer, G.S., Hsu-Kim, H., 2016. Trends in the Rare Earth Element Content of U.S.-Based Coal Combustion Fly Ashes. Environ. Sci. Technol. 50, 5919-5926. https://doi.org/10.1021/acs.est.6b00085

Tang, M. cheng, Zhou, C.C., Pan, J.H., Zhang, N.N., Liu, C., Cao, S.S., Hu, T.T., Ji, W.S., 2019. Study on extraction of rare earth elements from coal fly ash through alkali fusion - Acid leaching. Miner. Eng. 136, 36-42. https://doi.org/10.1016/j.mineng.2019.01.027

van der Lee, J., De Windt, L., 2002. CHESS Tutorial and Cookbook. Updated for version 3.0 (Users Manual No. Nr. LHM/RD/02/13). Fontainebleau, France.

Vigil, M., Marey-Pérez, M.F., Martinez Huerta, G., Álvarez Cabal, V., 2015. Is phytoremediation without biomass valorization sustainable? - Comparative LCA of landfilling vs. anaerobic $\begin{array}{lllll}\text { co-digestion. } & \text { Sci. } & \text { Total } & \text { Environ. }\end{array}$ https://doi.org/10.1016/j.scitotenv.2014.10.047

Wang, L.F., Ji, H.B., Bai, K.Z., Li, L.B., Kuang, T.Y., 2005. Photosynthetic characterization of the plant Dicranopteris dichotoma Bernh. in a rare earth elements mine. J. Integr. Plant Biol. 47, 1092-1100. https://doi.org/10.1111/j.1744-7909.2005.00138.x 
Wang, Y.B., Wang, Y.L., Su, X., Zhou, H.Y., Sun, X.Q., 2018. Complete separation of aluminium from rare earths using two-stage solvent extraction. Hydrometallurgy 179, 181-187. https://doi.org/10.1016/j.hydromet.2018.06.004

Wang, Y.D., Li, J.H., Gao, Yan, Yang, Y., Gao, Yang, Xu, Z.F., 2020. Removal of aluminum from rare-earth leaching solutions via a complexation-precipitation process. Hydrometallurgy 191, 105220. https://doi.org/10.1016/j.hydromet.2019.105220

Wang, Y.Q., Sun, J.X., Chen, H.M., Guo, F.Q., 1997. Determination of the contents and distribution characteristics of REE in natural plants by NAA. J. Radioanal. Nucl. Chem. 219, 99-103. https://doi.org/10.1007/BF02040273

Wang, Z., Dai, S.F., Zou, J.H., French, D., Graham, I.T., 2019. Rare earth elements and yttrium in coal ash from the Luzhou power plant in Sichuan, Southwest China: Concentration, characterization and optimized extraction. Int. J. Coal Geol. 203, 1-14. https://doi.org/10.1016/j.coal.2019.01.001

Wei, Z.G., Hong, F.S., Yin, M., Li, H.X., Hu, F., Zhao, G.W., Wong, J.W.C., 2005. Subcellular and molecular localization of rare earth elements and structural characterization of yttrium bound chlorophyll a in naturally grown fern Dicranopteris dichotoma. Microchem. J. 80, 1-8. https://doi.org/10.1016/j.microc.2004.07.005

Wei, Z.G., Yin, M., Zhang, X., Hong, F.S., Li, B., Tao, Y., Zhao, G.W., Yan, C.H., 2001. Rare earth elements in naturally grown fern Dicranopteris linearis in relation to their variation in soils in South-Jiangxi region (Southern China). Environ. Pollut. 114, 345-355. https://doi.org/10.1016/S0269-7491(00)00240-2

Whittington, B.I., 1996. The chemistry of $\mathrm{CaO}$ and $\mathrm{Ca}(\mathrm{OH}) 2$ relating to the Bayer process. Hydrometallurgy 43, 13-35. https://doi.org/10.1016/0304-386X(96)00009-6

Wolery, T.W., Jarek, R.L., 2003. Software user's manual. EQ36 Version 8, 376.

Yang, Q.C., Ma, S.H., Zheng, S.L., Zhang, R., 2014. Recovery of alumina from circulating fluidized bed combustion Al-rich fly ash using mild hydrochemical process. Trans. Nonferrous Met. Soc. China 24, 1187-1195. https://doi.org/10.1016/S10036326(14)63178-2

Yang, X.J., Lin, A.J., Li, X.L., Wu, Y.D., Zhou, W.B., Chen, Z.H., 2013. China's ion-adsorption rare earth resources, mining consequences and preservation. Environ. Dev. 8, 131-136. https://doi.org/10.1016/j.envdev.2013.03.006

Yang, X.L., Zhang, J.W., 2015. Recovery of rare earth from ion-adsorption rare earth ores with a compound lixiviant. Sep. Purif. Technol. 142, 203-208. https://doi.org/10.1016/j.seppur.2014.11.050

Zhang, X., Laubie, B., Houzelot, V., Plasari, E., Echevarria, G., Simonnot, M.-O., 2016. Increasing purity of ammonium nickel sulfate hexahydrate and production sustainability in a nickel phytomining process. Chem. Eng. Res. Des. 106, 26-32. https://doi.org/10.1016/j.cherd.2015.12.009 